\title{
Continuum Models of Ductile Fracture: A Review
}

\author{
J. BESSON* \\ Centre des Matériaux, Mines ParisTech \\ UMR CNRS 7633, BP 87, 91003 Evry Cedex, France
}

\begin{abstract}
The past 20 years have seen substantial work on the modeling of ductile damage and fracture. Several factors explain this interest. (i) There is a growing demand to provide tools which allow to increase the efficiency of structures (reduce weight, increase service temperature or load, etc.) while keeping or increasing safety. This goal is indeed first achieved by using better materials but also by improving design tools. Better tools have been provided which consist (ii) of material constitutive equations integrating a physically-based description of damage processes and (iii) of better numerical tools which allow to use the improved constitutive equations in structural computations which become more and more realistic. This article reviews the material constitutive equations and computational tools, which have been recently developed to simulate ductile rupture.
\end{abstract}

KEY WORDS: ductile rupture, models, numerical simulation.

\section{INTRODUCTION}

D REDiCTIVE NUMERICAL SIMULATIONS of ductile fracture may be of great interest in industrial situations for which full-scale experimental approaches are either too costly or even impracticable. This is the case of ductile tearing of gas pipelines over several hundred meters, of crack propagation in large nuclear vessels or of ductile tearing of aircraft fuselage. For such applications, simulations should predict crack paths, stability, stress states, etc. Several techniques may be used to achieve these objectives.

The approach based on Rice (1968) J-integral is widely used for industrial applications but suffers from various limitations: (i) It can only deal with preexisting cracks and cannot be applied to model crack initiation and propagation from a notch. (ii) It is not a material intrinsic property as it strongly depends on specimen geometry as experimentally shown in Sumpter and

*Author to whom correspondence should be addressed. E-mail: jacques.besson@ensmp.fr

International Journal of Damage Mechanics, Vol. 19-January 2010 
Forbes (1992) and Sumpter (1993) using single edge notch bending (SENB) specimens and center crack panels (CCP). This as led to the introduction of the $J-Q$ two parameters approach (O'Dowd and Shih, 1991, 1992). (iii) It can hardly be applied to complex geometries such as welds. In the case of welds, the $J-Q$ description of fracture proposed by O'Dowd and Shih, (1991) was extended to account for plastic mismatch between materials (Zhang et al., 1996, 1997). It was also proposed to compute local crack tip values for both $J$ and $Q$ (Kim et al., 1997, 1999). Approaches using critical crack top opening displacement (CTOD) or crack tip opening angle (CTOA) suffer from the same limitations (Dawicke et al., 1997; James and Newman, 2003; Mahmoud and Lease, 2003).

The limitations of the previous approach (so called 'Global Approach') have led to the development of more physically-based descriptions of fracture which belong to the 'Local Approach to Fracture"1 (Pineau, 1980; Berdin et al., 2004; Pineau, 2006). The approach is referred to as 'local' as a detailed and physically-based description of damage phenomena is used to represent the rupture process zone. Within this framework, damage and rupture can be represented on a surface (cohesive zone model) or in the volume (continuum damage mechanics). Both methods can be implemented in the finite element (FE) method.

The first approach is mainly limited to predefined known crack paths (Roychowdhury and Dodds Jr, 2002; Cornec et al., 2003) because they exhibit strong mesh dependency and over-estimate cracked areas if inserted between each volume element in a FE mesh (Scheider and Brocks, 2003). The model can clearly not account for diffuse ductile damage which occurs in metals before damage localization within a thin band. A nonpredefined crack path could possibly be modeled using advanced numerical techniques such as X-FEM (Sukumar et al., 2000) based on the partition of unity method and coupled with a cohesive zone model (Moes and Belytschko, 2002). Applications of this methodology are still limited to elastic solids (i.e., fatigue or brittle rupture) or small-scale yielding conditions.

Within the local approach, the second description of damage is based on a volume representation of degradation phenomena. This method is based on constitutive equations coupling plasticity and damage at the material point level so that the materials models are often referred to as 'Continuum Damage Mechanics' (CDM). Such models are reviewed in the following after a brief description of physical damage mechanisms leading to ductile rupture. Micromechanical models or descriptions are then presented; such approaches are used to derive semi-empirical constitutive equations which can be used in FE softwares and which can account for the three main stages of ductile rupture. A more phenomenological approach is then presented. Both approaches

\footnotetext{
${ }^{1}$ The term Local Approach to Fracture was first proposed by Pineau (1980) to describe this methodology.
} 
are compared. As damage growth leads to a strong decrease of the load bearing capacity (softening), FE simulations carried out with CDM models are prone to strain and damage localization so that results are not robust and strongly mesh size dependent. Some solutions to this problem are also reviewed. Some information is given about numerical techniques needed to perform simulation of ductile rupture. The conclusion focuses on the flat to slant fracture transition in thin sheets as this phenomenon is only partly understood and simulated and epitomizes most of the difficulties currently encountered in the domain of modeling and simulation of ductile fracture.

\section{PHYSICAL PROCESSES OF DUCTILE RUPTURE}

Ductile fracture can be described as a three stages process (see review in Garrison and Moody, (1987)). Voids are first initiated at material defects (mostly inclusions). Note that voids may also preexist in the material. Due to large plastic deformation, these voids then grow in particular in situations where the stress triaxiality is large. ${ }^{2}$ When voids are large enough they tend to coalesce to form microcracks and eventually a macroscopic crack that leads to macroscopic failure. Figure 1 gives several examples of ductile rupture for one aluminum alloy (2000 series) and various steels. Void initiating particles are coarse intermetallic particles containing Fe and Si (2024 aluminum alloy), elongated (X52 steel) or spherical (A508 steel) manganese sulfides (MnS), spherical CaS particles (X100 steel). These examples are ideal cases where only one inclusion type (in general the coarser ones) is at the origin of fracture. This situation prevails at high stress triaxialities. However, engineering alloys always contain several inclusion populations corresponding to different length scales. At low stress triaxialities, void nucleation in narrow bands of secondary voids is often observed. This failure mechanism is often referred to as 'void sheeting' (Garrison and Moody, 1987). Examples are given in Figure 2 for the 2024 aluminum alloy and the X100 steel which were used to illustrate primary cavity growth. In the first case (Figure 2(a)), dispersoids containing $\mathrm{Zr}$, Mn, or $\mathrm{Cr}$ are sites for secondary nucleation. In the second case (Figure 2(b)), $\mathrm{Fe}_{3} \mathrm{C}$ carbides can initiate secondary voids.

Observation and quantification of these processes can help developing relevant models and fitting model parameters required to perform structural simulations. Observations have, for a long time, been limited to studies of fracture surfaces and of polished cross sections of broken or damaged specimens. The recent development of X-ray tomography (see e.g., Maire et al., 2001; Morgeneyer et al., 2008) now allows the direct observation of bulk damage processes. Using this technique, error on damage quantification induced by

\footnotetext{
${ }^{2}$ The stress triaxiality ratio is defined as: $\tau=\frac{1}{3} \sigma_{\mathrm{kk}} / \sigma_{\mathrm{eq}}$ where $\sigma_{\mathrm{kk}}$ is the trace of the stress tensor and $\sigma_{\mathrm{eq}}$ the von Mises equivalent stress.
} 


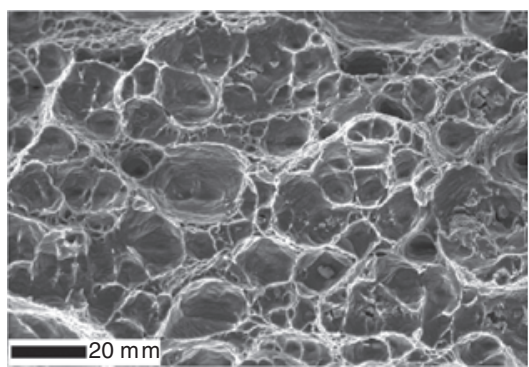

(a)

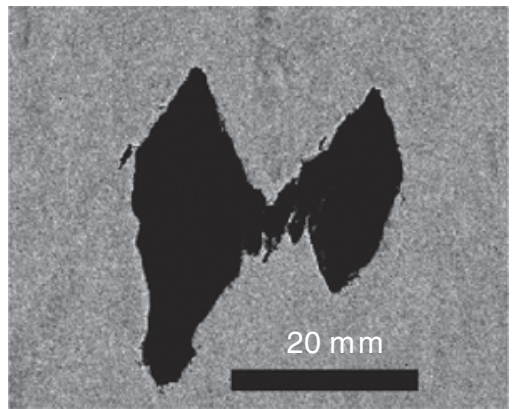

(c)

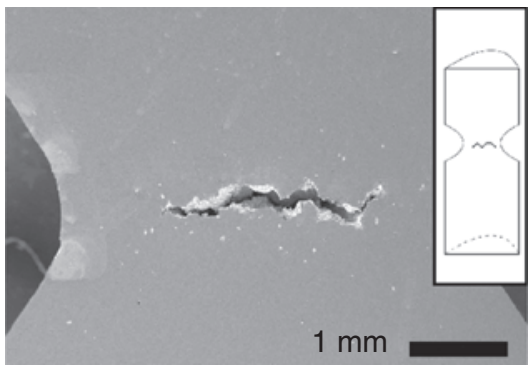

(b)

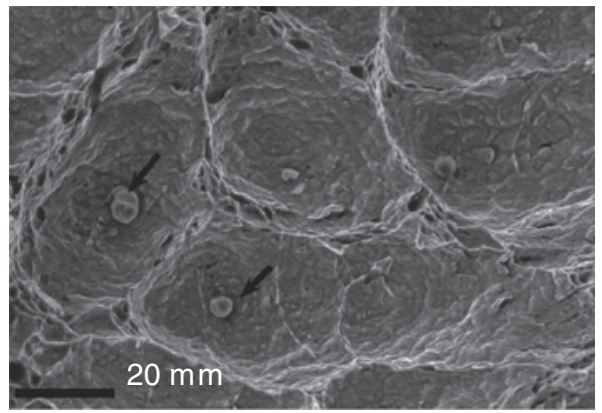

(d)

Figure 1. Examples of ductile failure by internal necking on voids initiated at primary inclusions. (a) Al 2024 (Bron, 2004): voids are initiated on coarse intermetallic particles containing Fe and Si. (b) A508 steel (Tanguy, 2001) formation of a macroscopic crack by void coalescence in a notched bar. (c) X52 steel (Benzerga, 2000): voids are initiated on manganese sulfides (MnS). The photograph of a cross section of the material shows the coalescence of two voids by internal necking. (d) X100 steel (Luu, 2006): voids are initiated on spherical CaS inclusions shown by arrows.

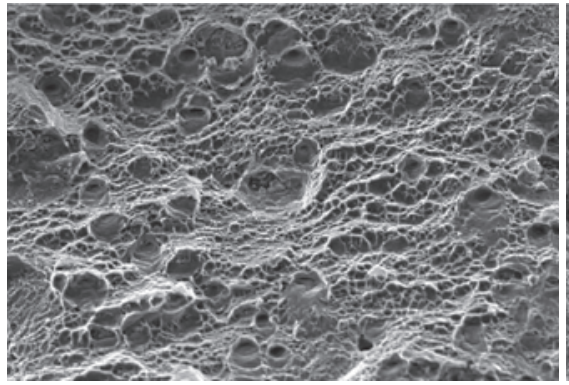

(a)
$20 \mu \mathrm{m}$

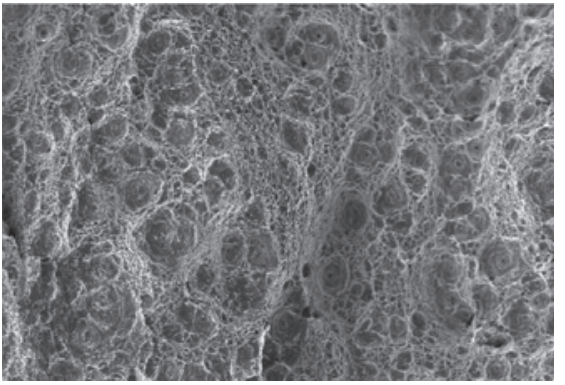

(b)
$100 \mu \mathrm{m}$

Figure 2. Examples of ductile failure involving two populations of cavities. (a) Al 2024 (Bron, 2004) secondary voids are nucleated on dispersoid particles having a typical size between 0.05 and $0.5 \mu \mathrm{m}$. These particles contain Zr, Mn, or Cr. (b) X100 steel (Luu, 2006): secondary voids are nucleated on $\mathrm{Fe}_{3} \mathrm{C}$ carbides. 


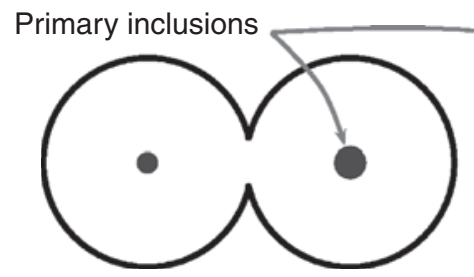

(a) Internal necking

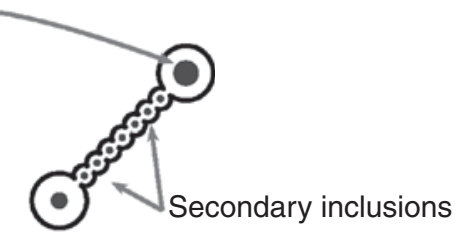

(b) Void sheeting

Figure 3. Ductile failure micromechanisms: (a) Failure by internal necking: large primary voids are formed due to high stress triaxiality; inter-void ligaments necks and fail with little or no nucleation of secondary voids. (b) Failure by void sheeting: primary voids remain small due to low stress triaxiality; secondary voids are nucleated in strain localization bands.

surface preparation can be avoided (Babout et al., 2001) and direct 3D information of damage (e.g., void/crack shapes) can be gathered (Figure 3).

\section{MICROMECHANICAL MODELING}

\section{Analytical Models for Void Growth}

The first micromechanical models for the development of ductile damage by McClintock (1968) and Rice and Tracey (1969) described the growth of isolated cylindrical or spherical voids in a rigid perfectly plastic matrix. Both studies outlined the combined role of stress triaxiality and plastic strain on ductile void growth. In the case of a spherical void (which is the more realistic one), the rate of variation of the void radius $R$ can be expressed (Rice and Tracey, 1969) for high stress triaxiality as:

$$
\frac{\dot{R}}{R}=\alpha \exp \left(\frac{3}{2} \frac{\sigma_{m}}{\sigma_{0}}\right) \dot{\varepsilon}_{\text {eq }}
$$

where $\alpha$ is a numerical factor, $\varepsilon_{\text {eq }}$ the von Mises equivalent strain and $\sigma_{0}$ the matrix yield stress. The initially proposed value for $\alpha(0.283)$ was modified by Huang (1991) to achieve a greater accuracy. The void growth model was also extended to account for strain hardening effects (Budianski et al., 1982; Becker et al., 1989). The Rice \& Tracey model for void growth has led to the definition of a simple rupture criterion stating that fracture occurs when the normalized void radius has reached a critical value:

$$
\left(R / R_{0}\right)=\left(R / R_{0}\right)_{c}
$$

where $R_{0}$ is the initial void radius. $\left(R / R_{0}\right)$ is computed integrating Equation (1) while $\left(R / R_{0}\right)_{c}$ is a material-dependent parameter defining the critical value for void growth (Marini et al., 1985). 
The previous analysis does not take into account the interaction between voids and the effect of void growth on material behavior (i.e., softening). This problem was first addressed by Gurson (1977) in an upper bound analysis of a finite sphere containing a spherical void in the case of a rigid perfectly plastic matrix. Damage is represented by the void volume fraction (or porosity), $f$, which here corresponds to the ratio of the volume of the void over the volume of the outer sphere. The result is the definition of a plastic yield surface which takes into account the porosity:

$$
\Phi=\frac{\sigma_{\mathrm{eq}}^{2}}{\sigma_{0}^{2}}+2 f \cosh \left(\frac{1}{2} \frac{\sigma_{k k}}{\sigma_{0}}\right)-1-f^{2}
$$

where $\sigma_{k k}$ is the trace of the stress tensor and $\sigma_{\text {eq }}$ the von Mises equivalent stress. The voided material yields under pure pressure $\left(\sigma_{\mathrm{eq}}=0\right)$ provided $f>0$. Failure occurs when the zero stress tensor matches the yield condition; in that case $f=1$. This implies that the material is made only of voids, which represents an optimistic prediction of failure! The derivation of the yield criterion made by Gurson implies that the normality rule applies to determine the plastic strain rate tensor, $\underline{\dot{\varepsilon}}_{p}$. The evolution of the porosity is then obtained applying mass conservation, so that:

$$
\dot{f}=(1-f) \operatorname{tr} \dot{\varepsilon}_{p}
$$

It is important to note here that the evolution law for the damage variable is entirely determined by the definition of the yield surface. More recently a Gurson-type analysis was proposed by Gologanu et al. $(1993,1994)$ to deal with axisymmetric prolate or oblate ellipsoidal cavities. Due to axisymmetry their shape is represented by a single shape factor, $S$, for which evolution laws are provided. The case of spherical voids in a matrix obeying the Hill (1950) yield criterion is treated in Benzerga and Besson, (2001). An expression coupling void shape and plastic anisotropy has been proposed by Monchiet et al. (2006, 2008). Other analytical expressions for the yield surface have been derived based on variational bounds in Michel and Suquet (1992) and Bonnenfant et al. (1998). They lead to a quadratic expression of the yield surface (see the following section).

\section{Unit Cell Modeling of Void Growth}

Analytical methods rely on simplifying assumptions in particular if closed-form solutions are searched. More accurate results may be obtained using numerical methods such as the FE method (Koplik and Needleman, 1988) or fast Fourier transform (Michel et al., 2001). These results can be 
used (i) to verify analytical solutions, (ii) to tune phenomenological models derived from these solutions, or (iii) to get a better understanding of damage processes. A useful configuration is provided by a meshed $3 \mathrm{D}$ box containing a single void of any kind of shape on which periodic boundary conditions are enforced. This generic situation is often simplified by considering a cylinder which has been shown to be representative of a 3D cell based on hexagonal symmetry (Kuna and Sun, 1996; Worswick and Pick, 1990). Examples of computational cell (referred to as unit cell) are given on Figure 4. Calculations are performed with either prescribed mean stresses or mean deformations. Prescribed stresses allow to control the mean stress triaxiality ratio and are often preferred. In that case, a Riks (1979) control method must be used to allow for decreasing stresses as void growth tends to weaken the unit cell. With increasing computational capabilities, it is now possible to represent cells containing several voids and to study the effect of clustering (Thomson et al., 2003; Bandstra and Koss, 2008).

\section{Void Nucleation}

The study of void nucleation using micromechanical modeling is much more limited than the study of void growth. This is due to intrinsic difficulties of the topic which requires to introduce specific material properties for the inclusions and in some cases for the inclusion/matrix interfaces. Depending on the particle size, modeling must either consider strain and stresses at the dislocation scale (small particles) or at the continuum mechanics scale (large particles). Inclusions are often considered as being purely elastic and brittle. Evaluation of stresses in the inclusion or at the matrix/inclusion interface can be used to derive nucleation criteria by particle cracking or interface decohesion. Cracking occurs if enough elastic
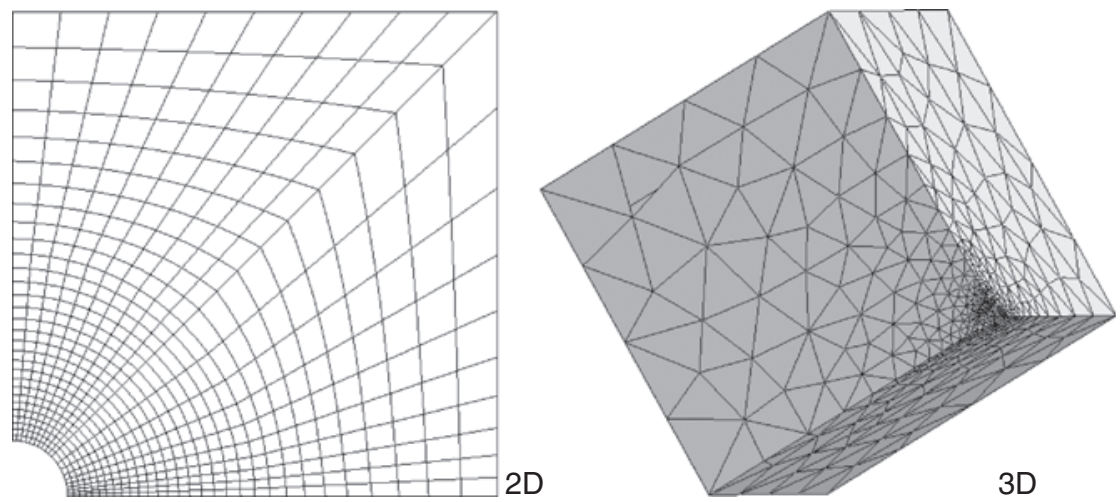

Figure 4. $2 D$ and $3 D$ unit cells for the evaluation of void growth models. 
energy can be released to create a new surface and if local stresses are higher than a material dependant critical value, $\sigma_{c}$. Goods and Brown (1979) showed that the energetic criterion is easily met provided particles are not too small. The analysis leads to an expression for the critical nucleation strain which is expressed as a function of the particle radius, the critical stress $\sigma_{c}$, the particle volume fraction and the macroscopic mean stress. The stress dependence is similar to that proposed by Argon et al. (1975). The nucleation strain varies linearly with particle size ; this is due to the fact that the interfacial stress decreases as the particle size increases (Goods and Brown, 1979). An opposite trend is obtained if one considers that the critical fracture stress, $\sigma_{c}$, decreases with particle radius due to a size effect commonly observed in brittle materials. The effect of the particle volume fraction is related to the strengthening effect of the particles on the flow stress of the material. It remains relatively small for usual values of the volume fraction.

At the continuum mechanics scale, strains and stresses can be evaluated using simplified analytical models or FE simulations of representative microstructures. Based on the results by Berveiller and Zaoui (1978), Beremin (1981) computed the maximal principal stress within the inclusion as:

$$
\sigma_{1}^{i}=\sigma_{1}+2 \mu^{p} \kappa \varepsilon_{\mathrm{eq}}^{p}
$$

where $\sigma_{1}$ is the macroscopic maximal principal stress, $\varepsilon_{\mathrm{eq}}^{p}$ the macroscopic von Mises plastic strain, $\mu^{p}$ the plastic secant or tangent shear modulus of the matrix. $\kappa$ is a geometrical factor depending on the inclusion shape. The previous formula can be rewritten as:

$$
\sigma_{1}^{i}=\sigma_{1}+\beta \kappa\left(\sigma_{\mathrm{eq}}-\sigma_{0}\right)
$$

where $\sigma_{\mathrm{eq}}$ is the macroscopic von Mises stress and $\sigma_{0}$ the material macroscopic yield strength. $\beta$ is a numerical factor which accounts for local matrix hardening. Nucleation is assumed to occur when $\sigma_{1}^{i}$ reaches a critical value. Note, although this aspect does not seem to have been addressed, that the critical stress for nucleation must be distributed to represent the experimentally observed nucleation kinetics. The previous analysis, as it is based on the Eshelby (1957) problem, assumes that stresses are homogeneous within the inclusion so that it is impossible to distinguish particle cracking and interface decohesion. Due to the nonlinear behavior of the matrix, the stress field is nonhomogeneous within the inclusion and the maximal stress normal to the interface is lower than the maximal principal stress within the particle, so that particle fracture and particle decohesion do 
not exactly follow the same criterion. FE simulations (see, e.g., Lee and Mear, 1999) must be used to capture these effects. More detailed simulations can be performed including particle damage (Steglich and Brocks, 1997; Steglich et al., 1999 or interface decohesion using cohesive zone models (Needleman, 1987, 1990; Segurado and Llorca, 2004).

\section{Void Coalescence}

As mentioned above, void coalescence may occur though: (i) void sheeting in which 'shear' bands are formed and (ii) internal necking (also referred to as void impingement). The first mechanism is often associated with the formation of secondary voids on very small particles. The first micromechanical analysis of void coalescence was proposed by Brown and Embury (1973). Coalescence is described, in this study, as the formation of $45^{\circ}$ micro-shear bands connecting two voids (i.e., void sheet mechanisms). The $45^{\circ}$ band can be formed when the distance between voids is approximately equal to their height. Coalescence by internal necking was described by Thomason $(1968,1985 a, b, 1990)$ based on a limit-load analysis of the ligament between voids. The model is described below. Finally, unit cell calculations can be used to study void coalescence, and for instance, to determine values of porosity at the onset of coalescence (Zhang et al., 2000).

\section{MICROMECHANICS-BASED CONSTITUTIVE MODELS}

\section{Generic Formulation of the Models}

Models derived from rigorous micromechanical analyses (e.g., the Gurson (1977) model) have been used to develop semi-empirical extensions relying on phenomenological descriptions of the different damage processes (i.e. nucleation, growth, and coalescence). In this section, a generic presentation of these micromechanics-based models is given (Besson and GuillemerNeel, 2003; Besson et al., 2001c):

It is first assumed that the material has an elastic behavior so that the strain rate tensor can be expressed as the sum of an elastic part $\left(\underline{\dot{\varepsilon}}_{e}\right)$ and a (visco)plastic part $\left(\dot{\varepsilon}_{p}\right)$ :

$$
\underline{\dot{\varepsilon}}=\dot{\varepsilon}_{e}+\dot{\varepsilon}_{p} .
$$

It is worth remembering that micromechanical analyses assume that the material is rigid-(visco)plastic. Stresses are then obtained using Hooke's law as: $\underline{\sigma}=\underline{\underline{E}}: \underline{\varepsilon}_{e}$ where $\underline{\underline{E}}$ is the elasticity fourth order tensor. ${ }^{3}$

\footnotetext{
${ }^{3} \underline{\underline{E}}$ can be expressed as a function of damage although this dependence is often neglected.
} 
The effect of porosity on plastic behavior is represented by the definition of an effective scalar stress $\sigma_{*}$ which is expressed as a function of the applied macroscopic stress tensor, the void volume fraction, and possibly void shape and void spacing. $\sigma_{*}$ is assumed to be a homogeneous positive function of degree 1 of $\underline{\sigma}$. To reflect the damaging effect of porosity, it is desirable that the effective stress should increase with $f$ for a given stress state so that: $\sigma_{*}\left(\underline{\sigma}, f_{1}\right)<\sigma_{*}\left(\underline{\sigma}, f_{2}\right)$ if $f_{1}<f_{2}$ where $f_{1}$ and $f_{2}$ are two porosity levels. $\sigma_{*}$ is interpreted as an effective matrix stress. The yield function is then expressed as

$$
\Phi=\sigma_{*}-R
$$

where $R$ represents the isotropic strain hardening of the matrix material. In the case of plastic materials, plastic flow occurs for $\Phi=0$ and $\dot{\Phi}=0$. For viscoplastic materials, flow occurs for $\Phi>0$. Applying the normality rule (which is known to be valid, based on the micromechanical analyses, provided it applies also to the matrix material), the plastic strain rate tensor is expressed as:

$$
\dot{\varepsilon}_{p}=\dot{\mu} \frac{\partial \Phi}{\partial \underline{\sigma}}
$$

where $\dot{\mu}$ is the plastic multiplier. One then assumes that isotropic hardening is described by a scalar variable $p$ which is interpreted as the plastic deformation of the matrix material so that (Shima and Oyane, 1976):

$$
\dot{\varepsilon}_{p}: \underline{\sigma}=(1-f) \dot{p} \sigma_{*}
$$

which expresses that the macroscopic plastic work (left-hand side) is equal to the microscopic plastic work (right-hand side). The factor $1-f$ corresponds to the fact that part of the macroscopic volume corresponds to pores in which plastic work is null. Using the hypothesis that $\sigma *$ is a homogeneous function of degree 1 , one gets: $\underline{\dot{\varepsilon}}_{p}: \underline{\sigma}=\dot{\mu} \sigma_{*}$ (Euler's Lemma) so that $\dot{\mu}=(1-f) \dot{p}$. The plastic strain rate tensor is finally expressed as:

$$
\dot{\varepsilon}_{p}=(1-f) \dot{p} \frac{\partial \Phi}{\partial \underline{\sigma}}
$$

As previously stated, the evolution of the porosity is given by mass conservation so that:

$$
\dot{f}_{g}=(1-f) \operatorname{tr} \dot{\varepsilon}_{p}
$$

where $f_{g}$ represents the change in porosity due to void growth. 
Void nucleation is introduced on a purely phenomenological basis. The nucleation rate is expressed as:

$$
\dot{f}_{n}=A_{n} \dot{p}
$$

where $A_{n}$ is the strain rate controlled nucleation rate. It may depend on several parameters such as the plastic strain $p$, the porosity $f$ but also the stress state. Stress controlled nucleation has also been proposed by Tvergaard (1990) but is not often used. The total porosity change rate is given by:

$$
\dot{f}=\dot{f}_{g}+\dot{f}_{n}
$$

\section{The 'Gurson-Tvergaard-Needleman' Model}

Following the work of Gurson (1977), it was soon recognized that the proposed yield surface was unable to represent fracture and coalescence. In addition, unit cell simulations showed that void growth rates were not accurately predicted. Tvergaad and Needleman (1984) then proposed to modify the expression of the original yield surface to be able to represent actual experiments as:

$$
\Phi=\frac{\sigma_{\mathrm{eq}}^{2}}{R^{2}}+2 q_{1} f_{*} \cosh \left(\frac{1}{2} q_{2} \frac{\sigma_{k k}}{R}\right)-1-q_{1}^{2} f_{*}^{2} .
$$

This model is often referred to as the Gurson-Tvergaard-Needleman (GTN) model. It introduces several new parameters: $q_{1}, q_{2}$ and $f_{*} . q_{1}$ and $q_{2}$ allow to more accurately describe void growth kinetics observed in unit cell computations. Based on early calculations (Koplik and Needleman, 1988) the values $q_{1}=1.5$ or $q_{1}=1.25$ and $q_{2}=1.0$ are often used. More recently, Faleskog et al. (1998) have shown that these parameters depend on the plastic hardening exponent and on the ratio of the yield stress over the Young's modulus. $f_{*}$ (which may be interpreted as an effective porosity) is a function of the actual porosity $f$. It was introduced to model coalescence in a rather crude but efficient way. It is assumed that when a critical porosity is reached, damage increase is faster due to coalescence. To represent this trend, the $f_{*}$ function is written as:

$$
f_{*}= \begin{cases}f & \text { if } f \leq f_{c} \\ f_{c}+\left(\frac{1}{q_{1}}-f_{c}\right) \frac{f-f_{c}}{f_{R}-f_{c}} & \text { otherwise }\end{cases}
$$


Rupture occurs when $f_{*}=1 / q_{1}$. The fracture porosity $f_{R}$ can be freely chosen. Although this particular form for $f_{*}$ is very often used, any other function could be suitable. Note that using low values for $f_{c}$ and $f_{R}$ can lead to convergence problems using the FE method. $f_{c}$ can be determined from unit cell calculations (Zhang et al., 2000).

A specific form for the nucleation rate $A_{n}$ proposed by $\mathrm{Chu}$ and Needleman (1980) is often associated with the GTN model. It is expressed as a Gaussian function:

$$
A_{n}=\frac{f_{N}}{s_{N} \sqrt{2 \pi}} \exp \left(-\frac{1}{2}\left(\frac{p-\varepsilon_{N}}{s_{N}}\right)^{2}\right)
$$

This law introduces three material parameters. $f_{N}$ : the volume fraction of inclusions at which damage can be nucleated; ${ }^{4} \varepsilon_{N}$ : the strain for which $50 \%$ of the inclusions are broken; $s_{N}$ : the standard deviation on the nucleation strain. In their numerical study, Chu and Needleman (1980) have used the following values: $\varepsilon_{N}=0.3, s_{N}=0.1$. This means that for $p=0.3$, half of the inclusions are broken and for $p=0.5,98 \%$ of the inclusions are broken. Many authors have used these values without any microstructural justifications although the nucleation rate undoubtedly depends on the type of material, its chemical composition and thermal treatments, etc. It is clear that many other forms (in particular based on experimental measurements of damage initiation) for $A_{n}$ can be chosen (see, e.g., (Zhang et al., 2000; Besson et al., 2000; Prat et al., 1998).

The GTN model can be made consistent with the generic framework presented above by defining the effective stress $\sigma *$ by the following implicit equation:

$$
\frac{\sigma_{\mathrm{eq}}^{2}}{\sigma_{*}^{2}}+2 q_{1} f_{*} \cosh \left(\frac{1}{2} q_{2} \frac{\sigma_{k k}}{\sigma_{*}}\right)-1-q_{1}^{2} f_{*}^{2} \equiv 0 .
$$

This equation is solved (Newton-Raphson algorithm) with respect to $\sigma *$ for given values of $f$ and $\underline{\sigma}$.

\section{Elliptic Models}

In the case of so called elliptic models, the effective stress is explicitly given by:

$$
\sigma_{*}=\sqrt{\frac{3}{2} \underline{\sigma}: \underline{\underline{M}}: \underline{\sigma}}
$$

\footnotetext{
${ }^{4}$ the volume fraction that can be nucleated is indeed equal; to $\int_{0}^{\infty} A_{n} d p$ whereas $f_{N}$ is exactly given by $\int_{-\infty}^{\infty}$ $A_{n} d p$. If $\mathrm{s}_{\mathrm{N}}$ is small enough with respect to $\varepsilon_{N}$ (which is positive), both integrals are approximately equal so that $f_{N}$ corresponds to the volume fraction of inclusion at which damage can be nucleated.
} 
where $\underline{\underline{M}}$ is a fourth-order tensor. In the case of an isotropic material, this equation reduces to: $\sigma_{*}=\sqrt{a \sigma_{\mathrm{eq}}^{2}+b \sigma_{k k}^{2}}$ where $a$ and $b$ are scalar parameters functions of $f . \underline{\underline{M}}$ depends on the porosity so as to assure that the behavior of the undamaged material is retrieved for $f=0$. This tensor may also depend on void shape parameters (Ponte-Castañeda and Zaidman, 1994).

The elliptic form for $\sigma_{*}$ was originally developed on a purely phenomenological basis (see, e.g., Green, 1972; Shima and Oyane, 1976; Abouaf et al., 1988) in order to introduce a pressure dependence in the expression of the yield surface. More recently, nonlinear estimates using homogenization techniques (Michel and Suquet, 1992; Ponte Castañeda and Suquet, 1998; Ponte-Castañeda and Zaidman, 1994) have led to the same kind of expression. The main drawback of elliptic models is that they predict a damage growth which varies linearly with stress triaxiality. This is true for linear viscous solids (Budianski et al., 1982) but obviously wrong for plastic materials for which the dependence is exponential following the Rice and Tracey (1969) or Gurson (1977) models. The model has been used to represent the behavior of highly porous materials such as metallic foams (Blazy et al., 2004).

An approximate model that coincides with the elliptic model for linear viscous solids and with the GTN model for plastic materials was proposed by Leblond et al. (1994). The effective stress is given by the following implicit equation (LPS model):

$$
\frac{\sigma_{\mathrm{eq}}^{2}}{\sigma_{*}^{* 2}}+q_{1} f^{*} \kappa_{M}\left(\frac{1}{2} q_{2} \frac{\sigma_{k k}}{\sigma_{*}}\right)-1-q_{1}^{2} \frac{1-M}{1+M} f^{* 2} \equiv 0
$$

with

$$
\kappa_{M}(x)=h_{M}(x)+\frac{1-M}{1+M} \frac{1}{h_{M}(x)} \quad \text { and } \quad h_{M}(x)=\left(1+M x^{1+M}\right)^{1 / M}
$$

where $M$ is the strain rate sensitivity. ${ }^{5}$ Two limiting cases are of particular interest. For $M \rightarrow 0$ the GTN model is retrieved as: $\lim _{M \rightarrow 0} \kappa_{M}(x)=$ $2 \cosh (x)$. For $M \rightarrow 1: \kappa_{M}(x)=1+x^{2}$ so that Equation (20) corresponds to an elliptic model.

\section{Void Shape and Void Rotation}

One of the major limitations of the Gurson model is that it can only handle the growth of spherical voids remaining spherical (which is only approximately true at intermediate stress triaxialities around 1.5). For nonspherical voids or when stress triaxiality is low so that voids tend to

\footnotetext{
${ }^{5}$ For an Norton like creep law expressed as $\dot{p}=\dot{\varepsilon}_{0}\left(\sigma_{\mathrm{eq}} / \sigma_{0}\right)^{n}, M=1 / n$ where $\dot{\varepsilon}_{0}$ and $\sigma_{0}$ are material parameters.
} 
become elongated, it is possible to use values for $q_{1}$ and $q_{2}$ tuned on unit cell simulations corresponding to the actual microstructure. In order to better cope with these situations, Gologanu and coworkers (Gologanu et al., 1993, 1994, 1997) have completely reworked the analysis in the case of ellipsoidal voids. The derivation by Gologanu assumed an axisymmetric ellipsoidal void located inside a confocal matrix. Derivations are extremely tedious due to the rigorous character of the analysis. It leads to a closed form expression for the yield surface of both elongated (prolate) and flat (oblate) voids which are loaded axisymmetrically. This model (referred to as GLD in the following) was validated by comparison to cell calculations (Gologanu et al., 1997; Pardoen and Hutchinson, 2000).

As the model considers axisymmetric ellipsoidal voids, a single shape parameter $S=R_{z} / R_{x}$, namely the cavity aspect ratio, is needed. $R_{z}$ is the void size along the symmetry axis and $R_{x}$ its size along the perpendicular directions, see Figure 5. The model is therefore limited to transversely isotropic porous plastic materials; it does not describe cavity rotation which occurs when the principal axes of deformation are not aligned with the cavity axes of symmetry so that the cavity is implicitly assumed to follow the rotation of the material. The model is formulated in terms of a Gurson-like plastic potential. The effective stress $\sigma_{*}$ is then defined as:

$$
\begin{aligned}
C \frac{\left\|\underline{\sigma^{\prime}}+\eta \sigma_{h} \underline{X}\right\|^{2}}{\sigma_{*}^{2}} & +2 q_{w}(g+1)(g+f) \cosh \left(\frac{\kappa \sigma_{h}}{\sigma_{*}}\right) \\
& -(g+1)^{2}-q_{w}^{2}(g+f)^{2} \equiv 0
\end{aligned}
$$
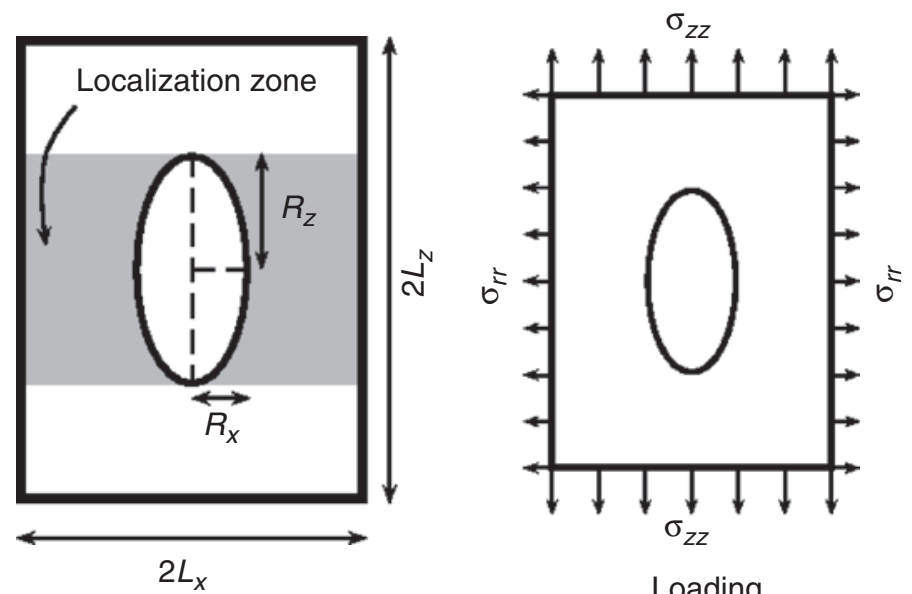

Loading

Figure 5. Geometry of Thomason model $\left(S=R_{z} / R_{x}\right)$. 
with:

$$
\sigma_{h}=\alpha\left(\sigma_{x x}+\sigma_{y y}\right)+(1-2 \alpha) \sigma_{z z} .
$$

$\underline{\sigma}^{\prime}$ is the stress deviator, $\|\cdot\|$ the von Mises norm. $C, \eta, q_{w}, g, \kappa$, and $\alpha$ are function of the porosity and the cavity shape factor. $\underline{X}=\frac{2}{3} \underline{e}_{z} \otimes \underline{e}_{z}-\frac{1}{3} \underline{e}_{x} \otimes$ $\underline{e}_{x}-\frac{1}{3} \underline{e}_{y} \otimes \underline{e}_{y}$ where $\left(\underline{e}_{x}, \underline{e}_{y}, \underline{e}_{z}\right)$ is an orthogonal basis with $\underline{e}_{z}$ parallel to the cavity axis. Some remarks can be made on the previous equations: (i) for round cavities $(S=1)$ Equation (22) is equivalent to Equation (18), (ii) for cylinders $(S \rightarrow+\infty), \alpha=\frac{1}{2}$ so that the stress along the cavity axis $\left(\sigma_{z z}\right)$ does not influence void growth, (iii) the function $g$ is equal to 0 for $S>1$ (elongated cavities); for flat cavities $(S<1), g$ is greater than 0 ; in particular for penny-shaped cracks $(S \rightarrow 0$ and $f=0$ ) $g$ is equal to the porosity corresponding to round cavities having the same projected area as the penny-shape crack. The evolution of the shape factor is given by an additional differential equation:

$$
\frac{\dot{S}}{S}=H \dot{\varepsilon}_{z z}^{p \prime}+K \dot{\varepsilon}_{m}^{p}
$$

where $\varepsilon_{z z}^{p \prime}$ is component of the deviator of the strain rate tensor along the cavity axis and $\dot{\varepsilon}_{m}^{p}$ the mean plastic deformation rate. $H$ and $K$ are parameters which depend on $f, S$ and the stress triaxiality $\tau$.

Models proposed in Ponte-Castañeda and Zaidman, (1994) and Kailasam and Ponte Castañeda (1998) for porous solids deal with 3D ellipsoidal pores and are not limited to axisymmetric cavities as in the case of the GLD model. The cavity mean deformation rate is obtained from the macroscopic plastic strain rate (elastic strains are assumed to remain small) using Eshelby (1957) theory with a Poisson's ratio equal to $1 / 2$ corresponding to the plastic incompressibility of the matrix. The evolution of the aspect ratios of the cavity are directly deduced from the cavity mean deformation rate. Using the Eshelby formalism also provides the cavity rotation rate (Kailasam et al., 2000; Aravas and Ponte Castañeda, 2004). As noted above this formalism is probably more suitable for linear viscous solids than for plastic solids. This problem was addressed by (Bordreuil et al., 2003; Maire et al., 2005) who described cavity rotation rate based on the representative theory developed by Wang (1970) for skew-symmetric tensor-valued functions. The model has adjustable parameters which can be fitted using unit cell calculations. It is shown that rotation rates for cavities in a linear viscous solid or in a plastic solid strongly differ. 


\section{Coalescence and Post-coalescence}

The model of coalescence proposed by Thomason $(1968,1985 a)$ assumes that coalescence initiates when the intervoid ligament reaches its plastic limit load. The model is derived using the axisymmetric unit cell depicted on Figure 5. The matrix material is assumed to be perfectly plastic (yield stress: $\sigma_{0}$ ). The voided material is represented as a regular array of cells containing ellipsoidal voids. The model introduces the cell aspect ratio $L_{z} / L_{x}$ as a new micromechanical parameter. Experimental observations (Figure 1, X52 steel) as well as unit cell calculations (Figure 4) prove the existence of the envisaged coalescence mechanism. The coalescence condition is obtained writing the mechanical equilibrium of the ligament (Figure 5):

$$
\pi\left(L_{x}^{2}-R_{x}^{2}\right) C_{f} \sigma_{0}=\pi L_{x}^{2} \sigma_{33}
$$

The force in the loading direction expressed in the ligament region (lefthand side) must be equal to the force applied on the cell boundary (righthand side). The cavity induces a stress concentration in the ligament thus increasing the ligament stress triaxiality. The load-carrying capacity of the ligament is therefore increased. This effect is described by the plastic constraint factor $C_{f}$ in the previous equation. In the case of the axisymmetric cell depicted in Figure 5, $C_{f}$ can be derived using the upper-bound theorem for limit-load analysis. The following expression gives an empirical expression for $C_{f}$ which is a close approximation of the upper-bound analysis (Thomason, 1985b):

$$
C_{f}=0.1\left(\frac{L_{x} / R_{x}-1}{S}\right)^{2}+1.2 \sqrt{L_{x} / R_{x}} .
$$

Noting that $\sigma_{33}=\left(\frac{2}{3}+\tau\right) \sigma_{\text {eq }}\left(\tau=\frac{1}{3} \sigma_{k k} / \sigma_{\text {eq }}\right.$ : macroscopic stress triaxiality ratio), the coalescence condition is expressed as:

$$
A_{m} C_{f}=\left(\frac{2}{3}+\tau\right) X(f, \tau) \quad \text { with } \quad A_{m}=1-\frac{\mathrm{R}_{x}^{2}}{\mathrm{~L}_{x}^{2}} .
$$

$X$ is defined as the ratio $\sigma_{\text {eq }} / \sigma_{0}<1$. The cell aspect ratio is related to the macroscopic deformation as:

$$
\frac{\left(L_{z} / L_{x}\right)}{\left(L_{z} / L_{x}\right)_{0}}=\exp \left(\frac{3}{2} \varepsilon_{z z}^{p^{\prime}}\right)
$$


where $\left(L_{z} / L_{x}\right)_{0}$ is the initial cell aspect ratio. In addition, using mass conservation one gets:

$$
\frac{R_{x}}{L_{x}}=\left(\frac{3}{2} f \frac{L_{z}}{L_{x}} \frac{R_{x}}{R_{z}}\right)^{1 / 3}
$$

Thomason's criterion for coalescence is purely based on geometrical considerations and the evolution of the microstructural parameters $f, S=R_{z} / R_{x}$ must be obtained using an appropriate model. This was initially done in Thomason (1985b) neglecting void growth and assuming the law of mixture to compute $X$ (i.e., $X=1-f$ ); void shape changes were accounted for using Rice and Tracey (1969) equations for the evolution of size and shape for isolated voids. The major drawback of this approach is that it neglects damage growth and therefore overestimates $X$. To overcome this drawback, it was proposed by Zhang and Niemi (1994, 1995b) to compute $X$ and $f$ using the Gurson model. Indeed, void shape change had to be neglected and pores were assumed to remain spherical. The model was used to compute the loading path dependent porosity at the onset of coalescence which is then used as $f_{c}$ in the GTN model (Zhang et al., 2000).

Following the previous approach the GLD model was used to predict $X, f$ and $S$ which are used to model coalescence (Benzerga et al., 1999; Pardoen and Hutchinson, 2000, 2003). This simplified model is consistent with unit cell calculations. For a given porosity flat cavities or elongated cells tend to decrease the ductility; in this case, the initial ligament is smaller than in the case of round cavities and regular spacing so that internal necking is easier. On the other hand, elongated voids and flat cells delay coalescence. These trends are more pronounced at low stress triaxialities as high triaxialities tend to produce round porosities.

As noted above, it has been proposed by Zhang and Neimi (1995b) to use Thomason's model of coalescence to derive the critical porosity $f_{c}$ used in the GTN model. However, this does not account for the modification of the plastic flow direction which occurs after coalescence. Unit cell calculations (Koplik and Needleman, 1988; Brocks et al., 1995) indicate that the deformation rate is equal to zero in directions perpendicular to the principal deformation direction. This implies that the ratio $\dot{\varepsilon}_{m}^{p} / \dot{\varepsilon}_{\mathrm{eq}}^{p}$ is equal to $\frac{1}{2}\left(\dot{\varepsilon}_{\mathrm{eq}}^{p}\right.$ : von Mises equivalent plastic strain rate). This is not accounted for by the GTN model. In addition, stresses must be such that the coalescence condition is still fulfilled in the post-coalescence regime. Rewriting Equation (27) leads to the following expression for the effective stress:

$$
\sigma_{\mathrm{eq}}+\frac{1}{2}\left|\sigma_{k k}\right|-\frac{3}{2} A_{m} C_{f} \sigma_{*} \equiv 0
$$


The material is therefore assumed to remain isotropic. Applying the normality rule leads to $\dot{\varepsilon}_{m} / \dot{\varepsilon}_{\text {eq }}=\frac{1}{2}$.

As noted by Pardoen and Hutchinson (2000), there are two modes of plastic deformation. The first one corresponds to diffuse plasticity and is described by the GTN model. The second one corresponds to localized plasticity during void coalescence. This implies that the yield surface is given by the intersection of two surfaces corresponding to each deformation mechanism. In their original work Pardoen and Hutchinson (2000) used the GLD model for the first surface; however any surface could be used (e.g., GTN model (Equation (18)) or LPS mode (Equation (20))). The situation where both surfaces intersect is described in Figure 6. At intersection points, the yield surface has a vertex and plastic flow may occur within the cone defined by the normals to each surface. Note that when porosity is low the Thomason yield surface does not intersect the GTN yield surface so that yielding is only defined by the latter.

The post-coalescence regime still requires the calculation of the microstructural parameters $S$ and $L_{z} / L_{x}$. Equation (28) is still valid but the rate equation for $S$ must be modified to account for the new cell kinematics. Based on unit cell calculations, it is assumed that the top of the void moves at the same velocity as the top of the cell (i.e., $\dot{R}_{z}=\dot{L}_{z}$ ). One then gets:

$$
\frac{\dot{S}}{S}=\frac{9}{4} \frac{L_{z}}{R_{z}} \dot{\varepsilon}_{z z}^{p \prime}\left(1-\frac{1}{2 \gamma} \frac{L_{x}^{2}}{R_{x}^{2}}\right)
$$

where $\gamma$ is an adjustable parameter used to represent the fact that the cavity shape is no longer ellipsoidal after the onset of coalescence as evidenced in Figure 1 (X52 steel for which cavities have a 'diamond' shape).

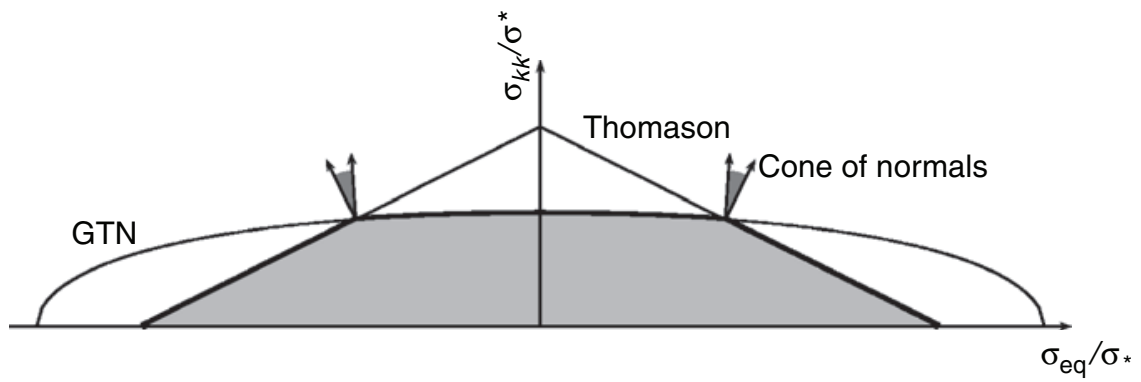

Figure 6. Definition of the yield surface (thick line) as the intersection of the GTN yield surface (Equation (18)) and the Thomason yield surface (Equation (30)). 


\section{Other Models and Extensions}

For the sake of completeness, it is worth mentioning extensions of the presented models as well as other models.

\section{PLASTIC ANISOTROPY}

Many materials are plastically anisotropic due to the processing method (e.g., hot rolling). It is therefore useful to extend the damage models to account for this effect. On a purely phenomenological basis, the Gurson model, as other models, can be extended using an anisotropic stress measure, $\bar{\sigma}$, instead of the von Mises stress. For example, GTN effective stress is now defined implicitly by:

$$
\frac{\bar{\sigma}^{2}}{\sigma_{*}^{2}}+2 q_{1} f \cosh \left(\frac{q_{2}}{2} \frac{\sigma_{k k}}{\sigma_{*}}\right)-1-q_{1}^{2} f^{2} \equiv 0
$$

where $\bar{\sigma}$ is an anisotropic stress measure. Various expressions for $\bar{\sigma}$ can be used. The Hill model (Hill, 1950) is often used (Doege et al., 1995; Rivalin et al., 2000; Grange et al., 2000b; Brunet and Morestin, 2001; Brunet et al., 2005) but more advanced models have been recently proposed to improve the representation of the yield surface (Barlat et al., 1991; Karafillis and Boyce, 1993; Bron and Besson, 2004). They can also be coupled with ductile damage models as in (Bron and Besson, 2006; Tanguy et al., 2008). The micromechanical Gurson-type analysis carried out by Benzerga and Besson (2001) shows that the previous equation can be rigorously derived in the case of Hill's criterion. Note that pores are assumed to remain spherical in this analysis.

\section{KINEMATIC HARDENING}

Modeling kinematic hardening is important in cases where loading is cyclic or nonproportional. Although the proposed extension can hardly be used in the case of fatigue (as fatigue micromechanisms do not correspond to those modeled by the Gurson approach), it may be useful to simulate the effect of a predeformation or of low cycle fatigue on the residual ductility The mathematical representation of kinematic hardening will not be recalled here; it is discussed in Lemaitre and Chaboche (1990) and Chaboche (2008).

Several extensions of the Gurson model for kinematic hardening to porous media have been proposed in the literature (Mear and Hutchinson, 1985; Leblond et al., 1995; Arndt et al., 1997; Besson and Guillemer-Neel, 2003; Ristinmaa, 1997). However, applications to actual test specimens or structures are still lacking. Unit cell calculations have also been performed 
as a validation of the models. Comparisons of FE calculations using either isotropic or kinematic hardening and constant damage parameters show that kinematic hardening accelerates the occurrence of failure.

\section{VOID/PARTICLE INTERACTION}

The above-described models assume that once a void has nucleated, the particle which served as nucleation site does not influence void growth. This is true as long as stress triaxiality is high enough so that void deformation is not constrained by the particle. At very low stress triaxialities (e.g., under pure shear) voids tend to strongly elongate along the direction of maximum deformation while they tend to shrink in the other directions. Shrinkage of the cavity in directions perpendicular to the direction of maximum deformation can be prevented by a particle so that porosity increases more than in absence of the particle. The model proposed to represent these effects by Siruguet and Leblond $(2004 a, b)$ is based on the GLD model to account for void shape change and modified to account for void locking by inclusions. The model can be used to represent rupture under pure shear.

\section{PHENOMENOLOGICAL CONSTITUTIVE MODELS}

Phenomenological constitutive models presented in this section are based on the work by Lemaitre $(1985,1996)$ which makes use of the early developments by Kachanov (1958). Many formulations slightly different from the one presented here are available in the literature. These models are often referred to as 'Continuum Damage Mechanics' (CDM) (Krajcinovic, 1996; Lemaitre, 1996). This terminology, however, appears improper as micromechanically based models also rely on a continuous description of damage. They are referred to as 'phenomenological' in this text as their development is essentially based on macroscopic considerations. Damage is represented by a scalar $(D)$ or tensorial $(\underline{D}, \underline{D})$ variable. Tensorial damage can either be related to material characteristic properties as in composites or to loading path. To cope with cyclic loading the model incorporates kinematic hardening in a much easier way than micromechanically based models. In addition damage closure under compression can also be accounted for. The specific model developed in this section and its various applications (including brittle fracture, creep, and fatigue) are fully developed in (Lemaitre, 1996; Lemaitre and Desmorat, 2005). The models are written within a consistent thermodynamic framework (Germain et al., 1983) which, in particular, guarantees that dissipation is always positive. This property can also be demonstrated 
for micromechanics-based models provided void nucleation is absent (Besson and Guillemer-Neel, 2003).

\section{Model with Isotropic Damage}

In this section the simplest version of the model is presented. It relies on four internal variables: the plastic strain tensor $\varepsilon_{p}$, an isotropic hardening variable $r$, a kinematic hardening variable $\underline{\alpha}$, and a scalar damage variable $D$. The free energy is expressed as:

$$
\psi=(1-D) \frac{1}{2}\left(\underline{\varepsilon}-\underline{\varepsilon}_{p}\right): \underline{\underline{E}}:\left(\underline{\varepsilon}-\underline{\varepsilon}_{p}\right)+G(r)+\frac{1}{3} C \underline{\alpha}: \underline{\alpha}
$$

from which thermodynamic forces associated to each variable can be derived:

$$
\begin{aligned}
& \underline{\sigma}=-\frac{\partial \psi}{\partial \underline{\varepsilon}_{p}}=(1-D) \underline{\underline{E}}:\left(\underline{\varepsilon}-\underline{\varepsilon}_{p}\right) \\
& Q=\frac{\partial \psi}{\partial r}=G^{\prime}(r) \\
& \underline{X}=\frac{\partial \psi}{\partial \underline{\alpha}}=\frac{2}{3} C \underline{\alpha} \\
& Y=-\frac{\partial \psi}{\partial D}=\frac{1}{2} \underline{\varepsilon}_{e}: \underline{\underline{E}}: \underline{\varepsilon}_{e}
\end{aligned}
$$

The minus sign in Equation (34) and Equation (37) is used for convenience to obtain standard Hooke's law between the elastic strain and the stress tensor and so that $Y \geq 0$. $Y$ corresponds to a elastic strain energy release rate. Other modified versions are used by Saanouni (2006) or Castagne et al. (2003) in the context of metal forming applications. To determine plastic flow it is necessary to define a yield criterion and a dissipation potential. The yield criterion is defined as:

$$
\Phi=\|\underline{\tilde{\sigma}}-\underline{X}\|-\sigma_{0}-Q
$$

where $\|\cdot\|$ denotes the von Mises norm. $\underline{\tilde{\sigma}}$ is the effective stress tensor defined as

$$
\underline{\tilde{\sigma}}=\underline{\sigma} /(1-D)
$$


which corresponds to the stress acting on a fictitious undamaged configuration. The dissipation potential is defined as: $\Psi=\Phi+F_{X}+F_{D}$ where $F_{X}$ is equal to:

$$
F_{X}=\frac{3 \gamma}{4 C} \underline{X}: \underline{X}
$$

for nonlinear kinematic hardening and $F_{X}=0$ for linear kinematic hardening. The contribution to the dissipation potential corresponding to damage may be written as:

$$
F_{D}=\frac{S}{(1+s)(1-D)}\left(\frac{Y}{S}\right)^{1+s}
$$

but other forms for $F_{D}$ may be used. In the previous equations, $\gamma, C$, s, and $S$ are material parameters which need to be adjusted. The evolution rates of the state variables are given by the dissipation potential as:

$$
\begin{aligned}
\dot{\varepsilon}_{p} & =-\dot{\lambda} \frac{\partial \Psi}{\partial(-\underline{\sigma})}=\frac{\dot{\lambda}}{1-D} \underline{\tilde{n}} \\
\dot{r} & =-\dot{\lambda} \frac{\partial \Psi}{\partial Q}=\dot{\lambda} \\
\dot{\alpha} & =-\dot{\lambda} \frac{\partial \Psi}{\partial \underline{X}}=\dot{\lambda}\left(\underline{\tilde{n}}-\frac{3 \gamma}{2 C} \underline{X}\right) \\
\dot{D} & =-\dot{\lambda} \frac{\partial \Psi}{\partial(-Y)}=\dot{\lambda} \frac{\partial \Psi}{\partial Y}=\frac{\dot{\lambda}}{(1-D)}\left(\frac{Y}{S}\right)^{s}
\end{aligned}
$$

where

$$
\underline{\tilde{n}}=\frac{3}{2} \frac{\underline{\tilde{\sigma}}^{\prime}-\underline{X}}{\|\underline{\tilde{\sigma}}-\underline{X}\|}
$$

Noting that $\underline{\tilde{n}}: \underline{\tilde{n}}=1$ and $\dot{r}=\dot{\lambda}$ one gets $\dot{p}=\dot{r} /(1-D)$ where $\dot{p}$ is the von Mises equivalent plastic strain rate. The use of convex dissipation potential assures that the intrinsic dissipation, $\mathcal{D}$, is positive ; it is expressed as: $\mathcal{D}=\underline{\sigma}: \underline{\dot{\varepsilon}}_{p}-Q \dot{r}-\underline{X}: \underline{\alpha}+Y \dot{D}$. Using Equations (42)-(45) it can be shown that: $\mathcal{D} \geq 0$.

Using the previous evolution law for $D$, damage starts to increase as soon as plasticity starts. It is possible to introduce damage thresholds based either on the cumulated plastic strain or on the stored energy to obtain a more realistic description of damage initiation (Lemaitre et al., 2000). A slightly 
modified version of the model (the expression of $F_{D}$ is modified) was used in Bonora, (1997) and Bonora and Milella (2001) to model ductile failure.

\section{Anisotropic Damage}

The extension of the previous model to damage anisotropy is not straightforward. The damage variable may be a fourth-order tensor (Chaboche, 1981; Krajcinovic, 1985; Tang et al., 1999; Armero and Oller, 2000; Hammi et al., 2004) or a second-order tensor (Cordebois and Sidoroff, 1982; Murakami, 1983; Chow and Wang, 1987, 1988a,b; Voyiadjis and Kattan, 1999; Lemaitre et al., 2000), which is easier to handle. One of the earliest generalization of Lemaitre's ductile damage model to anisotropic damage was done by Chow and Wang (1987) in a very consistent way. Following the work by Cordebois and Sidoroff (1982) and Lemaitre et al. (2000) in the case of a second-order tensor, the effective stress tensor is now defined as:

$$
\underline{\tilde{\sigma}}=\underline{\underline{J}}:(\underline{H} \cdot \underline{\underline{J}}: \underline{\sigma}) \cdot \underline{H})+\frac{\sigma_{k k} / 3}{1-\eta D_{k k} / 3} \underline{1}
$$

where $\underline{J}$ is the fourth-order tensor such that $\underline{J}: \underline{a}$ is equal to the deviator of $\underline{a}$. $\eta$ is a model parameter and $\underline{H}$ is given as: $\underline{\bar{H}}=(\underline{1}-\underline{D})^{-1 / 2} \cdot{ }^{6}$ Based on this definition of the effective stress tensor, Equations (42)-(44) remain valid. The isotropic evolution law for $D$ has to be generalized. It was proposed in Lemaitre et al. (2000) to express the damage rate as:

$$
\underline{\dot{D}}=\left(\frac{Y}{S}\right)^{s}\left|\dot{\varepsilon}_{p}\right|
$$

where $Y$ is still given by: $\frac{1}{2} \underline{\varepsilon}_{e}: \underline{\underline{E}}: \underline{\varepsilon}_{e}$ Using this evolution law in uniaxial tension, damage in directions perpendicular to the loading direction is one half of the axial damage. However, in a biaxial tensile test, damage in the third direction is twice the damage in the tensile directions which is not realistic. The previous relation can be modified for instance using the positive part of $\dot{\varepsilon}_{p}$ rather than its absolute value.

\section{Damage Closure}

Under cyclic or complex loading paths, microcracks and microvoids can close so that the material recovers, at least partially, its initial properties. To model this effect the strain energy release rate $Y$ is modified in order to give a different treatment for tensile and compressive stress states

\footnotetext{
${ }^{6}$ If $F$ is a scalar valued function of a scalar, $F(\underline{a})$ is computed as follows: (i) compute the eigenvalues of $\underline{a}$, (ii) apply $F$ to each eigenvalue to build $F(\underline{a})$ in the eigenframe, (iii) transport $F(\underline{a})$ in the initial reference frame.
} 
(Lemaitre, 1996; Andre pires et al., 2003). The main difficulty is to recognize what is compression and what is tension in a multiaxial $3 \mathrm{D}$ stress state and to provide a continuous relation between the stress tensor and the elastic strain tensor. In the case of isotropic damage and isotropic elasticity (Young's modulus: $E$; Poisson's ratio: $v$ ), $Y$ is now defined as:

$$
\begin{aligned}
Y= & \frac{1+v}{2 E}\left(\frac{\langle\underline{\sigma}\rangle_{+}:\langle\underline{\sigma}\rangle_{+}}{(1-D)^{2}}+h \frac{\langle\underline{\sigma}\rangle_{-}:\langle\underline{\sigma}\rangle_{-}}{(1-h D)^{2}}\right) \\
& -\frac{v}{E}\left(\left(\frac{\operatorname{tr}\langle\underline{\sigma}\rangle_{+}}{1-D}\right)^{2}+h\left(\frac{\operatorname{tr}\langle\underline{\sigma}\rangle_{-}}{1-h D)^{2}}\right)\right.
\end{aligned}
$$

where $\langle\underline{a}\rangle_{+}$(resp. $\langle\underline{a}\rangle_{-}$) represents the positive (resp. negative) part of tensor $\underline{a}$. Parameter $h \leq 1$ describes the effect of closure. For $h=1$ there is no closure and the original model is recovered. For $h=0$ damage growth is equal to zero under compression as $Y=0$. Closure only affects elastic properties and damage kinetics. The yield condition is still written using Equation (38) so that damage still affects yielding when closure is active. The effect of closure on yielding could possibly be accounted for taking into account frictional sliding at the microcrack level as this is done in the case of quasi-brittle materials (see, e.g., Halm and Dragon, 1998). The possibility to extend the description of closure to anisotropic damage is presented in ( $\mathrm{Ju}$ (1989); Chaboche (1993) and Halm and Dragon (1998)) for quasi-brittle materials and has been the subject of many developments for concrete and composites. In the context of ductile damage, these extensions were given in Lemaitre et al. (2000) and Desmorat and Cantournet (2008).

\section{The Rousselier Model}

The model proposed by Rousselier $(1987,2001)$ is based on the thermodynamical framework proposed in Lemaitre and Chaboche (1990) and introduces a damage variable as a state variable. However, the associated 'thermodynamical' force and the yield surface must be such that the damage evolution law corresponds to mass conservation (i.e., Equation (12)). The damage variable is consequently identified as the porosity and the yield surface is expressed as:

$$
\Phi=\frac{\sigma_{\mathrm{eq}}}{(1-f)}+\sigma_{1} f D \exp \left(\frac{\sigma_{k k}}{(1-f) \sigma_{1}}\right)-R
$$

$D$ and $\sigma_{1}$ are material parameters that need to be determined. Based on this definition, the previous equation cannot be used to define an effective stress 
which would be a homogeneous function of $\underline{\sigma}$ (Besson et al., 2001c) as in the case of the GTN model (Equation (15) is transformed into Equation (18)). At this point, it is interesting to outline some differences between the Gurson and Rousselier models. Under pure shear $\left(\sigma_{k k}=0\right)$, damage is still generated in the case of the Rousselier model whereas, in absence of nucleation, the Gurson model does not lead to damage growth. Under pure hydrostatic stress states $\left(\sigma_{\mathrm{eq}}=0\right)$, the Rousselier yield surface has a vertex which implies that at high stress triaxiality ratios the plastic deformation tensor always keeps a nonzero shear component. Note that the models proposed in Fleck et al., (1992) for plastic metal powders or in Pastor et al., (2004) for voided solids have the same property and that the vertex is also deduced from Thomason analysis of coalescence (Figure 6). The model was recently extended to model damage in polycrystalline materials (Rousselier and Leclercq, 2006). In order to have a formulation for the Rousselier model compatible with the generic model formulation presented above while keeping the above-mentioned properties, the Rousselier model was extended in Tanguy and Besson (2002). The effective stress is then defined as:

$$
\frac{\sigma_{\mathrm{eq}}}{(1-f) \sigma_{*}}+\frac{2}{3} f D_{R} \exp \left(\frac{q_{R}}{2} \frac{\sigma_{k k}}{(1-f) \sigma_{*}}\right)-1 \equiv 0
$$

\section{COMMENTS ON BOTH TYPES OF MODELS}

In this section, the differences between micromechanical and phenomenological models are outlined.

\section{Volume Change}

Models based on the work by Kachanov (1958) and Lemaitre (1985) clearly do not represent plastic volume variation and consequently void growth as the yield condition uses the stress or effective stress deviator. An attempt has recently been made in (Hammi and Horstemeyer, 2007) to explicitly account for nucleation, growth and coalescence within the Lemaitre framework. The different mechanisms each contribute to damage evolution but the actual volume change is not represented. On the other hand, micromechanical models as well as the Rousselier model provide a straightforward description of volume change.

\section{Damage Nucleation}

Due to the absence of volume change, phenomenological models are essentially describing damage nucleation. Considering that volume change is 
small, void growth can be treated using the Lemaitre formalism and model parameters can be tuned to mimic the stress state dependence obtained with the GTN model (Lemaitre and Desmorat, 2005). The main advantage of the phenomenological models, as far as nucleation is concerned, is that they provide a consistent thermodynamical framework, which cannot be clearly established in the case of the GTN model including nucleation (Besson and Guillemer-Neel, 2003). It would be useful to combine the Lemaitre formalism for nucleation together with the GTN model for void growth. This has been attempted by Chaboche et al. (2006) in the case of an elliptic model. If void growth is prohibited in the case of a micromechanical model, nucleation damage can be linked to the variable $D$ used in CDM phenomenological approaches. For instance in the case of the GTN model for $q_{2}=0$ (or in the case of pure shear loading) Equation (18) reduces to $\sigma_{*}=\sigma_{\mathrm{eq}} /\left(1-q_{1} f_{*}\right)$ so that $D$ can be identified to $q_{1} f_{*}$.

\section{Effect of Damage on Elastic Behavior}

Coupling between damage and elastic behavior plays an important role in the Lemaitre phenomenological model in particular to derive the consistent thermodynamic framework and the driving force for damage growth. However, this model can be simplified by neglecting coupling between damage and elastic behavior. The effective stress tensor is still used to define the yield condition (Equation (38)) and an independent evolution law is used for the evolution of damage (see, e.g., Xue, 2007). In the case of the micromechanical models and of the Rousselier model, elastic properties may be written as function of damage but this dependence is very often neglected. Tests show that its effect on simulations is very limited.

\section{Strain Rate Sensitivity}

One assumes here that the matrix material is rate dependent and that the flow stress increases with increasing strain rates. In the case of the Lemaitretype model, increasing strain rate leads to a higher damage rate as stresses and consequently the strain energy release rate, $Y$, increase (Equation (45)). A different dependence is obtained by adding the energy stored by hardening (Saanouni, 2006; Cherouat et al., 2002); in that case an increasing damage rate still results from an increase of strain rate.

Unit cell calculations performed using a rate-dependent matrix (Tanguy and Besson, 2002) showed that void growth is not affected by strain rate. The generic model presented above is consistent with these results which is not the case of the Lemaitre model or of the Rousselier model if one considers that $\sigma_{1}$ constant. In that case the ratio $\sigma_{k k} / \sigma_{1}$, which drives damage growth, 
increases with increasing strain rate so that porosity increases faster. This trend can be corrected considering that $\sigma_{1}$ is strain rate dependent (Sainte Catherine et al., 2002) or using the modified Rousselier model proposed in Tanguy and Besson (2002).

Damage nucleation by particle cracking or decohesion is very likely to depend on the stress state. Based on micromechanical analysis of nucleation nucleation rate is likely to increase with increasing stresses and stress triaxiality (Guillemer-Neel et al., 2000a,b). This trend is consistent with the Lemaitre-type model; this confirms that this model is essentially representative of nucleation. The dependence of damage nucleation on stress state is often neglected using the GTN model although it can be accounted for using stress-controlled nucleation (Tvergaard, 1990) or stress triaxiality-dependent nucleation rate parameter $A_{n}$ (Gaffard et al., 2005). Once again, coupling the Lemaitre formalism for nucleation and the Gurson model for void growth could be interesting.

\section{Miscellaneous Comments}

Kinematic hardening is more easily introduced using the phenomenological models; it has been mainly used to model low cycle fatigue. It has been hardly used in the case of micromechanical models. However, accounting for this effect could be important to describe the effect of prestraining on ductility (Bao and Treitler, 2004; Enami, 2005).

Damage anisotropy described by the GLD model is limited to axisymmetric cavities and axisymmetric loading; proposed extensions to 3D cases (Pardoen and Hutchinson, 2000) should be used with care. The model proposed by Kailasam and Ponte Castañeda (1998) is not suitable for plastic materials but deals with the generic 3D cases. The description proposed by the phenomenological models is generic but most suitable for nucleation controlled anisotropy as noted above.

Damage closure is accounted for by micromechanical models as voids may grow but also shrink and closure corresponds to $f_{g}=0$. Closure in presence of nucleation has not been addressed yet but care must be taken when integrating constitutive equations to assure that $f_{g}$ remains positive. The phenomenological models can deal with this problem although anisotropic damage closure remains a difficult topic.

\section{STRAIN AND DAMAGE LOCALIZATION}

Due to the strong softening character of the constitutive equations, development of damage leads to strain localization in the material. Conditions for the development of localized zones are presented in the 
following for rate-independent solids and rate-dependant solids. The thickness of the localization band cannot be predicted by such approaches. This implies that FE simulations are strongly mesh size dependent and that reducing mesh size does not produce a converged solution.

\section{Bifurcation Analysis for Rate-independent Solids}

In the case of elastoplastic materials, the incremental constitutive equation can be expressed as:

$$
\underline{\underline{o}}=\underline{\underline{L}}_{t}: \underline{D}
$$

$\underline{\underline{L}}_{t}$ is the elastoplastic tangent matrix, $\underline{D}$ the strain rate and $\underline{\underline{\sigma}}$ the Jaumann $\overline{\bar{d}}_{t}^{t}$ rivative of the stress tensor. $\underline{\underline{L}}_{t}$ indeed depends on the set of constitutive equations and will not be explicitly derived here. Localization is assumed to occur in an infinite planar band characterized by its normal $\vec{n}$. Displacement is assumed to be discontinuous across this band. The direction of the displacement jump is referred to as $\vec{g}$ (Figure 7). Writing the continuity of displacements and the stress equilibrium, it can be shown (Rice, 1976, 1980) that the jump of the deformation tensor is proportional to:

$$
\frac{1}{2}(\vec{g} \otimes \vec{n}+\vec{n} \otimes \vec{g})
$$

and that the condition for bifurcation is written as (Rice, 1980; Mear and Hutchinson, 1985):

$$
\exists \vec{n}, \quad \operatorname{det}\left(\underline{A}_{t}(\vec{n})\right)=0
$$

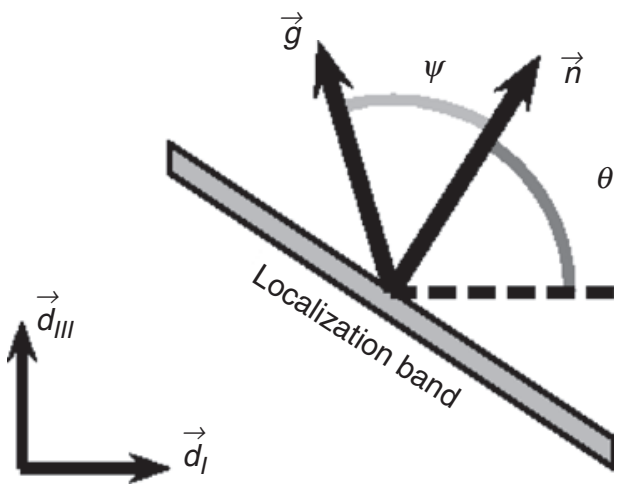

Figure 7. Geometry of the localization band. 
with:

$$
\underline{A}_{t}(\vec{n})=\vec{n} \cdot \underline{\underline{L}}_{t} \cdot \vec{n}+\frac{1}{2}((\vec{n} \cdot \underline{\sigma}) \otimes \vec{n}-\vec{n} \otimes(\vec{n} \cdot \underline{\sigma})+(\vec{n} \cdot \underline{\sigma} \cdot \vec{n}) \underline{1}-\underline{\sigma})
$$

where the second term of the right-hand side is due to the finite strain formalism using the Jaumann stress rate. $\vec{g}$ is then the eigenvector of $\underline{A}_{t}(\vec{n})$ corresponding to the eigenvalue equal to zero. This condition corresponds to continuous bifurcation (plastic yielding on each side of the band). Discontinuous bifurcation (plastic yielding on one side and elastic unloading on the other side) corresponds to $\operatorname{det} \underline{A}_{t}(\vec{n})<0$ (Rice, 1980, Borré and Maier, 1989).

The localization band is schematically represented in Figure 7 . The band normal, $\vec{n}$, lies in the plane defined by the eigenvectors corresponding to the maximum $\left(\vec{d}_{I}\right)$ and minimum eigenvalues $\left(\vec{d}_{I I I}\right)$ of the strain rate tensor provided dilatancy is not too large (Rudnicki and Rice, 1975; Yamamoto, 1978). The angle $\psi$ characterizes the type of failure which varies from pure opening fracture $\psi=0$ to pure tangential fracture $\left(\psi=\frac{\pi}{2}\right)$.

A 'localization indicator' can be derived from the previous analysis. It can be used to post-process simulations in order to detect areas where localization is possible (Billardon and Doghri, 1989; Besson et al., 2001c, 2003). The indicator is obtained by minimizing $\operatorname{det}\left(\underline{A}_{t}(\vec{n})\right)$ over all possible band orientations:

$$
I_{b}=\min _{\vec{n},\|\vec{n}\|=1} \operatorname{det}\left(\underline{A}_{t}(\vec{n})\right)
$$

Band formation can occur as soon as $I_{b}=0$. The band normal is given by the vector $\vec{n}$ for which $I_{b}=0$.

\section{Perturbation Analysis for Rate-Dependant Solids}

In the case of rate-dependant solids relation (52) does not hold and the previous analysis cannot be applied. In that case, the linear perturbation analysis can be applied. The method consists in analyzing, inside an homogeneous volume element, the stability of a perturbation of the displacement field. The method is fully developed in Fressengeas and Molinari (1985), Anand et al., (1987), Rousselier (1991, 1995) and Barbier et al. (1998). Localization is assumed to occur when the rate of variation of the perturbation is much larger than the rate of variation of the unperturbed solution. It can therefore be difficult to precisely determine localization as the analysis does not specify a given critical value for the ratio of both variation (perturbed and unperturbed) rates. In order to circumvent this difficulty, it was proposed to use the consistent tangent matrix, which is 
defined for rate-dependant materials, together with the bifurcation analysis (Besson et al., 2001c).

\section{Mesh Size Sensitivity and Need for a Characteristic Length}

As mentioned earlier, localization of strain and damage occurs during FE calculations using constitutive equations inducing softening and eventually fracture. The purpose of this section is to illustrate this effect on a practical case study which could be used as a benchmark test. The calculations of this section are carried out with a material considered as elastoplastic. Damage is modeled using the GTN model. The material parameters are summarized in Table 1.

Calculations are carried out using quadrangular plane strain linear elements (four nodes) with full integration (four Gauss points). To avoid pressure oscillations, selective integration is used (Hughes, 1980; Simo et al., 1985) (this method is also referred to as B-bar method). The numerical test is performed on a $\mathrm{C}(\mathrm{T})$ specimen (Compact Tension) which is schematically represented in Figure 8. The initial crack tip is located at $27.5 \mathrm{~mm}$ from the load line. The area ahead of the crack tip where the crack will propagate is meshed with regular square elements. The zone behind the crack tip is also meshed using the same element size to allow a good description of the crack tip opening displacement (CTOD). Contact between the loading pin and the sample is not accounted for. The sample is loaded by applying a vertical displacement on the center of a wedge (light gray in Figure 8) modeled as an elastic body having the same elastic properties as the actual material. The center of the wedge is located at the center of the hole machined in the $C(T)$ specimen. Figure 9 shows the Force versus Crack Mouth Opening Displacement (CMOD) curve for various mesh sizes (initial elements are assumed here to be square but other shapes can be used). The figure clearly illustrates the mesh size effect and the absence of convergence when mesh size is decreased.

Table 1. GTN model parameters used in the case study. These parameters can be used to model ductile fracture of 16MND5 pressure vessel steels.

\begin{tabular}{ll}
\hline Elasticity & $\begin{array}{c}\text { Young's modulus } E=198 \mathrm{GPa}, \\
\text { Poisson's ratio } v=0.3\end{array}$ \\
Plasticity & $R(p)=1013 *(p+0.005)^{0.14}$ \\
GTN (void growth) & $q_{1}=1.5, q_{2}=1.0, f_{0}=0.0005$ \\
GTN (nucleation Equation (17)) & $\varepsilon_{N}=0.1, f_{N}=0.006, s_{N}=0.1$ \\
GTN (coalescence Equation (16)) & $f_{c}=0.01, f_{R}=0.34$ \\
\hline
\end{tabular}

$f_{0}$ : initial void volume fraction. 
The effect of mesh size on crack initiation can be explained as follows: stress and strain gradients are very high at the crack tip. For a given applied displacement, the deformation computed for Gauss points close to the crack tip will be larger for fine meshes. This leads to an earlier initiation. The role of mesh size on crack propagation can be interpreted as follows. The mechanical work dissipated per crack increment by inelastic deformation in one FE having the dimensions $w$ (width), $b$ (thickness), and $h$ (height) is:

$$
U_{d}=\int_{V_{e}} \int_{0}^{t_{R}}\left(\underline{\sigma}: \mathrm{d} \underline{\varepsilon}_{p}\right) \mathrm{d} V_{e}
$$

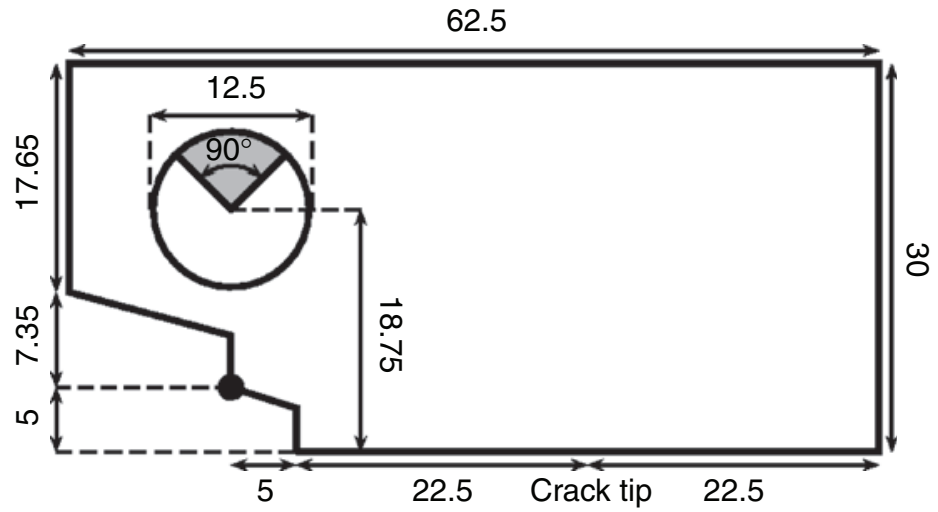

Figure 8. Dimensions of the simulated $\mathrm{C}(\mathrm{T})$ specimen $(\mathrm{mm})$. The black dot represents the location of the CMOD measurement.

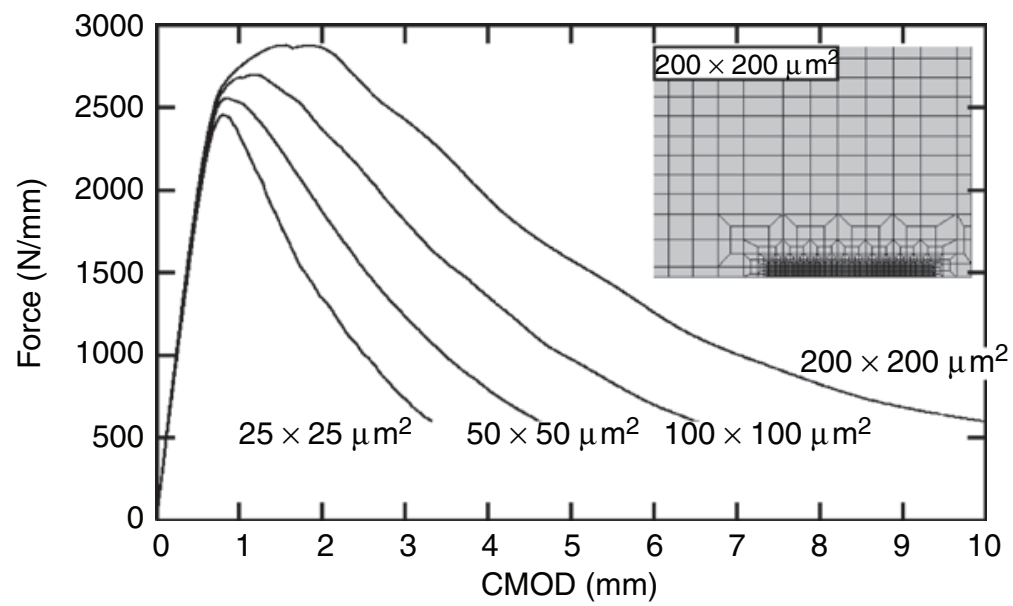

Figure 9. Simulations of $C(T)$ specimens using different mesh sizes: Force-CMOD curves. A view of the mesh along crack growth path is also shown. 
where $V_{e}$ is the volume of the element and $t_{R}$ the time at which the element is considered as broken. Considering that the volume of the element remains almost constant, the previous equation can be rewritten as:

$$
U_{d}=u_{d} V_{e}=u_{d} h w b
$$

where $u_{d}$ is a rupture energy per unit volume. At $t_{R}$ the element is considered as broken; this correspond to a crack extension of area $\Delta a=w b$ so that the energy dissipated per crack extension increment is equal to:

$$
\Gamma_{0}=\frac{U_{d}}{\Delta a}=\frac{u_{d} h w b}{w b}=u_{d} h \propto h .
$$

$\Gamma_{0}$ is interpreted as a specific 'work of separation' (Siegmund and Brocks, 1999). By increasing the element height, more mechanical work is dissipated. This affects, of course, the global behavior of the structure. In the present case, the relation between $\Gamma_{0}$ and the overall structural behavior is complex as large scale yielding conditions prevail. $u_{d}$ depends on the local load history. In particular $u_{d}$ depends on the local constraint: $u_{d}$ is likely to be high for low local stress triaxiality ratios and low for high triaxialities. The dependence of $u_{d}$ and therefore $\Gamma_{0}$ on the local history makes it difficult to have a direct correspondence between continuum damage models and cohesive zone models as noted in Siegmund and Brocks (1999).

\section{Mesh Size as a Material Parameter?}

The mesh size dependence evidenced above is not surprising and is directly related to material softening induced by damage growth. A direct consequence it that diminishing the mesh size does not lead to converged results. The pragmatic solution adopted to solve this problem is to consider the mesh size as a material parameter that needs to be adjusted (Rousselier, 1987; Liu et al., 1994; Ruggieri and Dodds, 1996). The need for a characteristic distance to properly model crack growth is also not surprising as this need also exists for simple uncoupled models such as the RKR model for brittle fracture (Ritchie et al., 1973) or the Rice and Tracey model for ductile fracture (Rice and Tracey, 1969; Beremin, 1981). The main problem following this approach is that mesh size has two different (and somehow conflicting) purposes: (i) geometrically represent the cracked parts, (ii) represent a material characteristic length controlling crack extension.

When using a fixed size, the selected mesh size is often related to the mean inclusion spacing $\lambda$. The material is seen as an assembly of cells of size $\lambda$ containing a single inclusion/void. This simple description does not account 
for the cell deformation or the role of secondary inclusions which are often smaller with a smaller mean spacing. Experiments carried out on aluminum alloys (Hahn and Rosenfield 1975) and on spheroidal cast iron (Steglich and Brocks, 1998) support this interpretation. In the later case, two materials containing the same volume fraction of graphite inclusions of different sizes were compared in terms of crack growth resistance. For a fixed volume fraction the mean spacing is proportional to the particle size. The material containing the larger inclusions showed a better resistance than the other one as could be expected. Moreover, GTN parameters adjusted for the larger inclusions material could be transferred directly to the other material by changing the mesh size according to the equation: $h_{\text {small }}=$ $\left(\lambda_{\text {small }} / \lambda_{\text {large }}\right) h_{\text {large. }}$ A similar technique was used in Bron and Besson (2006) in the case of two aluminum alloys.

\section{Nonlocal Damage Models}

In order to solve the mesh dependency problem, so called 'nonlocal' models have been proposed. These models were initially proposed in the framework of elasticity (Kröner, 1967; Eringen and Edelen, 1966) and were rapidly extended in the cases of plasticity and damage. They all assume that the behavior of the material at a given material point, $\vec{x}$, does not only depend on the local values of the different state variables but also on the values of one or several variables in a domain around $\vec{x}$. The size of this domain allows introducing a material characteristic length scale independently on any mesh size. Several modeling strategies can be used to account for this neighborhood effect.

The first one relies on an integral definition of the nonlocal variable $v_{\mathrm{nl}}$ as (Bazant and Pijaudier-Cabot, 1988):

$$
v_{\mathrm{nl}}(\vec{x})=\int_{\Omega(\vec{x})} \Phi\left(\vec{x}^{\prime}-\vec{x}\right) v_{1}\left(\vec{x}^{\prime}\right) \mathrm{d} x^{\prime}
$$

where $v_{1}$ is the local variable. $\Phi$ is a weighting function. $\Omega(\vec{x})$ is the volume of the domain around material point $\vec{x}$ in which $\Phi$ is not equal to 0 . The previous equation should be solved implicitly within the FE method framework. This implies a complex implementation as the integration volume $\Omega(\vec{x})$ should extend over several FE. This problem can be bypassed by explicitly incrementing the nonlocal variable after each load increment as proposed in Saanouni et al. (1989) so that

$$
v_{\mathrm{nl}}^{n+1}(\vec{x})=v_{\mathrm{nl}}^{n}(\vec{x})+\int_{\Omega(\vec{x})} \Phi\left(\vec{x}^{\prime}-\vec{x}\right) \Delta v_{1}^{n}\left(\vec{x}^{\prime}\right) \mathrm{d} x^{\prime}
$$


where $v_{\mathrm{nl}}^{n}\left(\right.$ resp. $\left.v_{\mathrm{nl}}^{n+1}\right)$ is the value of the nonlocal variable at increment $n$ (resp. $n+1) . \Delta v_{1}^{n}$ is the increment of the local variable computed at increment $n$ after convergence. The numerical implementation of this simplified method is indeed much easier but convergence of the numerical procedure is not assured. This method was also employed in the case of the Gurson model by Enakoutsa et al. (2007). In that case the nonlocal variable is $\log (f)$. The explicit implementation of the nonlocal model is, in this work, consistent with the fact that $f$ is explicitly integrated.

The nonlocality can also be introduced using gradients of material variables (Aifantis, 1987; Lorentz and Andrieux, 2003). Following the developments by Peerlings et al. (1996), the following implicit differential equation can be proposed to obtain the evolution of the nonlocal variable:

$$
v_{\mathrm{nl}}-\nabla\left(l_{c}^{2} \nabla v_{\mathrm{nl}}\right)=v_{1}
$$

where $l_{c}$ is the material characteristic length. Assuming that this quantity is constant one gets:

$$
v_{\mathrm{nl}}-l_{c}^{2} \Delta_{\mathrm{nl}}=v_{1}
$$

Using the Taylor expansion of Equation (60) it can be shown that this gradient-based method is equivalent to the integral method. Its main advantage is that it is simple to implement as the nonlocal variable can be defined as a nodal variable in the FE method framework. On the other hand the explicit version of the model, which is expressed as $v_{\mathrm{nl}}-\nabla\left(l_{c}^{2} \nabla v_{1}\right)=v_{1}$, required the evaluation of the gradient of the Gauss point variable $v_{1}$ and is more difficult to implement. This method has been applied in the case of the GTN model in Reusch et al. (2003). The implicit nonlocal scheme was recently extended to anisotropic damage in composite materials considering anisotropic characteristic lengths (Germain et al., 2007). Material constitutive equations must then be complemented and written as a set of relations between $\left(\underline{\varepsilon}, v_{\mathrm{nl}}\right)$ and $\left(\underline{\sigma}, v_{1}\right)$.

Instead of relying on state variables to introduce nonlocality, it is possible to use enhanced theories (Forest and Sievert, 2006) which account for spacial derivatives of the displacement fields up to 2 as in second-gradient theories (Mindlin and Eshel, 1968). Following this theory additional degrees of freedom are introduced to represent the rotation and deformation of an underlying microstructure. The most general case is the micromorphic theory (Eringen and Suhubi, 1964) as nine additional degrees of freedom are added corresponding to a micro-deformation and a micro-rotation. Simplified versions of this generic model can then be derived. Considering volume change only, leads to a micro-dilatation theory which can be useful 
in the case of ductile damage by void growth only (Bargellini et al., 2007). Considering micro-rotation only, corresponds to the Cosserat model (Cosserat and Cosserat, 2009; De Borst, 1991; Forest et al., 2000). Considering micro-rotation and micro-dilatation corresponds to the micro-stretch model (Eringen, 1990). Finally, considering micro-deformation and neglecting micro-rotation leads to the micro-strain model (Forest and Sievert, 2006).

\section{NUMERICAL SIMULATION OF DUCTILE RUPTURE}

In order to use the above-described models in structural computations, they need to be implemented in FE softwares. In addition crack advance must be properly managed in order to avoid numerical difficulties. These points are discussed in the following.

\section{Implementation of the Constitutive Equations}

Constitutive equations are expressed using state variables V. Rate equations are given to express the evolution of these variables; they are expressed as:

$$
\dot{\mathbf{V}}=\dot{\mathbf{V}}(\mathbf{V}, t, \underline{\dot{\varepsilon}})
$$

where time $t$ is used to prescribe independent variables such as temperature. The previous equation can be integrated with respect to time using either an explicit adaptive scheme (i.e., Runge-Kutta method) or an implicit method (so called $\theta$-method) (see, e.g., Besson et al., 2001b; Berdin et al., 2004). The explicit implementation is straightforward. The implicit integration procedure is more complex and has been detailed in several publications (Aravas, 1987; Simo, 1987a,b; Doghri, 1995; Zhang, 1995b,a; Zhang and Niemi, 1995a; Mahnken, 1999; Kailasam et al., 2000; Besson et al., 2001c; Kim and Gao, 2005). Using an implicit integration procedure allows to easily compute the consistent tangent matrix needed to compute the elementary stiffness matrices (Simo and Taylor, 1985).

Ductile rupture is always accompanied by large deformations so that a finite strain formalism must be used when implementing constitutive equations. Specific implementations using the finite strain formalism proposed by Simo (1992) and Simo and Miehe (1992) have been used by Mahnken (1999) and Reusch et al. (2003). An easier treatment of finite strain may be obtained using generic formulations based on reference frames which allow to keep the standard small strain formulation (i.e. using an additive strain decomposition as in Equation (7)). One of those formulations 
uses the corotational reference frame which is characterized by the rotation $Q_{c}$ whose evolution is governed by the following differential equation (Sidoroff and Dogui, 2001):

$$
\underline{\dot{Q}}_{c}=\underline{\Omega} \cdot \underline{Q}_{c} \quad \text { with } \quad \underline{Q}_{c}(t=0)=\underline{1}
$$

where $\underline{\Omega}$ is the skew-symmetric part of the transformation gradient rate $\underline{L}=\underline{\dot{F}} \cdot \underline{F}^{-1}$ where $\underline{F}$ is the transformation gradient. The material deformation rate is given by: $\underline{\dot{\varepsilon}}=Q^{T} \cdot \underline{D} \cdot \underline{Q}$ where $\underline{D}$ is the symmetric part of $\underline{L}$. The corresponding objective stress rate is the Jaumann rate.

\section{Modelling Crack Growth}

Rupture of a material point corresponds to a full loss of load-carrying capacity. This implies that stresses are equal to zero whatever the deformation and that the consistent tangent matrix is also null. To prevent numerical difficulties the 'broken' material can be replaced by an elastic behavior with a very low Young's modulus (Liu et al., 1994). Elements with a sufficiently high number of 'broken' Gauss points can then be removed from the calculation. This technique is simpler than remeshing and degrees of freedom belonging to removed elements only must be fixed. This element removal technique works relatively well as elementary nodal forces associated to nodal displacements tend to zero as damage grows.

Remeshing is also an interesting method to propagate cracks. This technique was applied by Bouchard et al. (2000) and Brokken et al. (2000) using a model without damage coupled with criteria for rupture and crack growth direction. Using history-dependent variables to describe plasticity and damage requires the transfer of these variables from the old to the new mesh (Borouchaki et al., 2005). In the case of strain localization, in particular for damage problems, it becomes difficult due to the need to preserve the localized character of the solution. During the process of transfer, the diffusion of internal variables should be limited. To achieve this goal, global projection methods on the whole domain or projections on element patches are not suitable and an element by element interpolation technique can be used (Ortiz and Quigley, 1991; Aubry et al., 2003). More recently, remeshing was applied in the case of nonlocal models (Mediavilla et al., 2006a,b).

\section{Parameter Identification}

Damage models introduced in the previous sections introduce numerous material parameters that need to be adjusted. The adjustment can usually not be performed using experimental results obtained on 'volume element' 
geometries (i.e., test samples where strains and stresses can be considered as uniform) as commonly done when identifying models for nondamaging plastic materials. This difficulty directly arises from the aim pursued when using damage models: simulating crack initiation and propagation. This implies that the database used to identify the model must include tests where initiation and propagation are involved.

Adjustment is performed by comparing experiments and simulations. Optimum model parameters are searched to minimize the difference. This can be done by 'trial and error' or automatically using an optimization program (see, e.g., (Mahnken, 1999) in the case of the GTN model). One of the difficulty, specific to the damage models, is that simulations involve crack propagation. These simulations are time consuming and very sensitive to the material parameters, which makes automatic identification difficult.

Input data for parameter fitting are indeed the macroscopic loaddisplacement curves obtained on various types of specimens. This includes tensile bars, compression bars, notched tensile bars, cracked specimens, plane strain specimens, Charpy specimens, etc. The material models used in the framework of the local approach are based on a physical description of the damage processes. This implies that some of the material coefficients can directly be measured on micrographs before or after failure (Grange et al., 2000a; Besson et al., 2000). Local field measurements (e.g., displacement at crack tip, CTOD, etc.) can also be used as input data. Therefore a way is provided to take into account data that can enrich the database or help in selecting the appropriate model.

\section{CLOSURE: FLAT TO SLANT TRANSITION}

To conclude this review an example is given which epitomizes the main difficulties encountered in the field of modeling and simulating ductile fracture. The example is concerned with testing of notched or precracked thin metal sheets. Fracture initiation at the notch or precrack root results from the formation of a flat triangular region (i.e., the normal to the crack corresponds to the loading direction). In this area large primary dimples are observed as shown in Figure 1. Once the initial triangle is formed, the crack tilts and becomes slanted as depicted in Figure 10 forming approximately an angle of $45^{\circ}$ with the loading direction. In this area, primary dimples are observed together with secondary dimples as shown in Figure 2. Figure 10 gives two examples of this phenomenon for an aluminum 2024 sheet and a X00 steel plate. Figure 11 shows a 2D X-ray synchrotron radiation tomography cross section of an interrupted Kahn tear (ASTM-B871, 2001) test carried out on a $2139 \mathrm{~T} 8$ aluminum sheet in the transition zone between flat and slant fracture. 

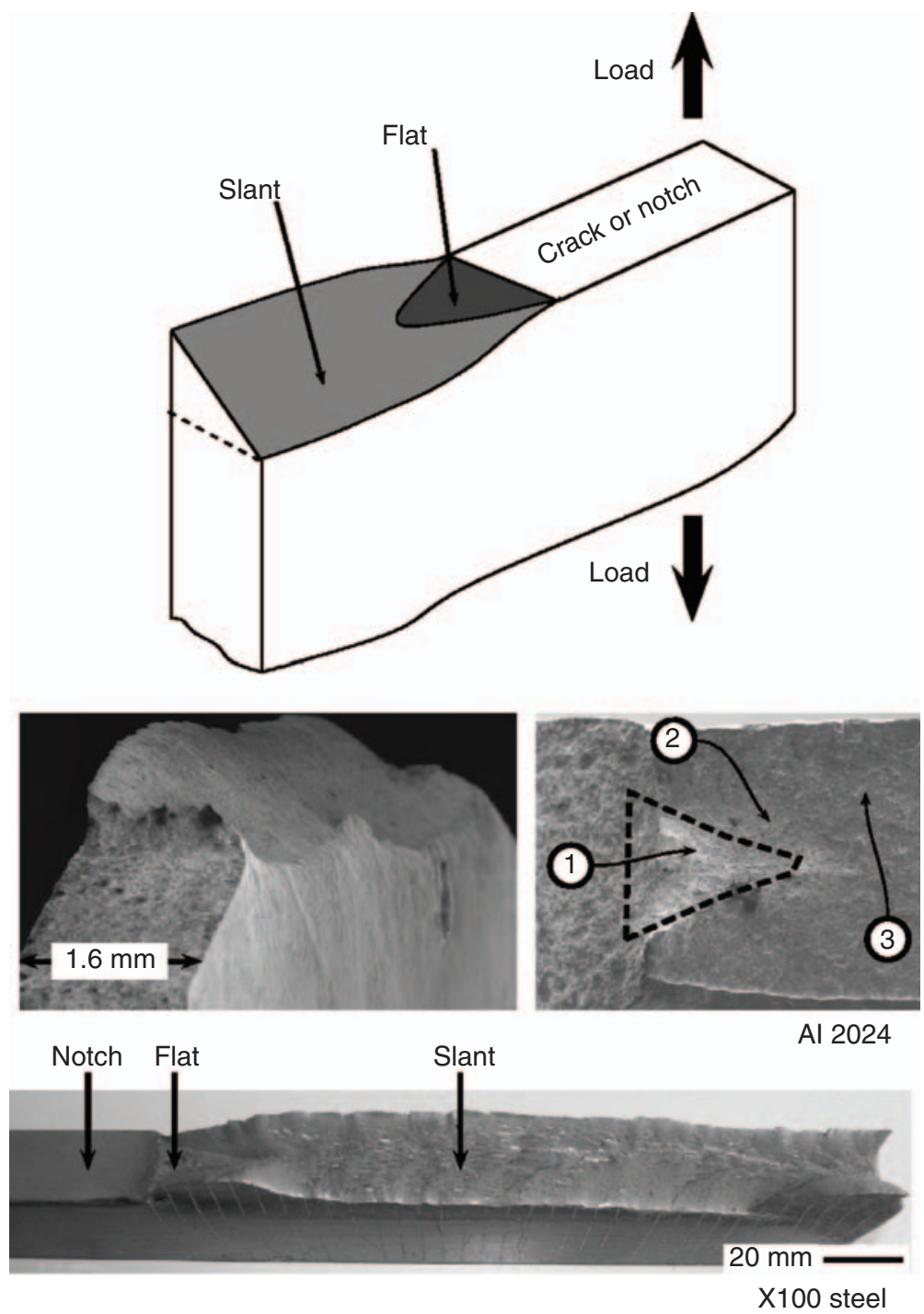

Figure 10. Flat to slant transition in metal sheets. Examples are given for an aluminum alloy (type 2024) and a high-strength steel (X100).

The problem has been qualitatively analyzed in Bron et al., (2004) and Bron and Besson (2006) using a simplified FE simulation of the test. In slanted regions the mean stress, $\sigma_{k k} / 3$, is small and the strain state corresponds to plane strain conditions in the propagation direction. The failure of the specimens is essentially controlled by a plastic instability 


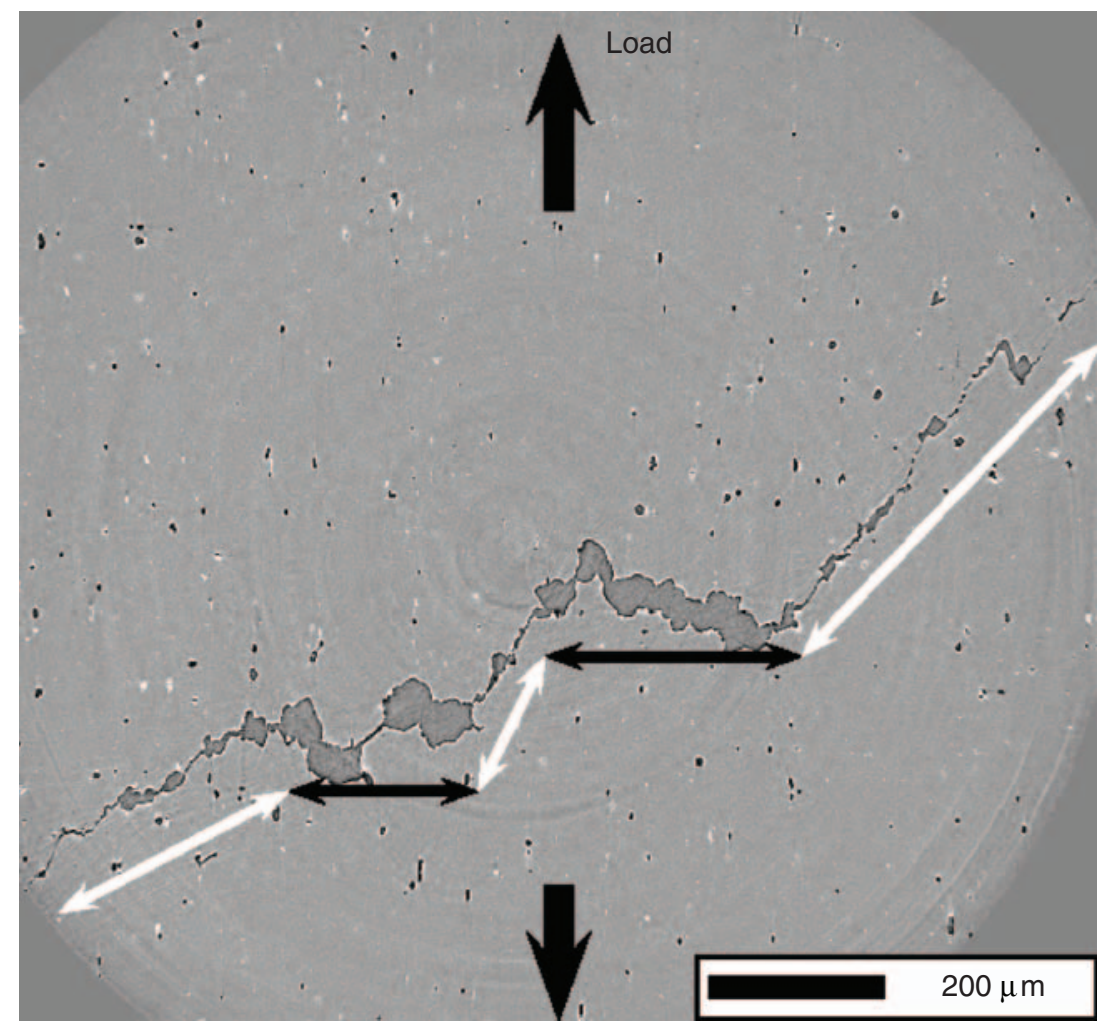

Figure 11. $2 D X$-ray synchrotron radiation tomography cross section of an interrupted Kahn tear (ASTM-B871, 2001) test showing the transition area between flat (black arrows) and slant (white arrows) fracture (courtesy T.F. Morgeneyer/ 2139 T8 aluminum sheet).

phenomenon, that is the localization of plastic deformation into a shear band. This situation also prevails in smooth tensile specimens and slightly notched samples for which the mean stress is even smaller thus explaining the smaller enlargement of primary voids. Near the notch root of severely notched samples, the mean stress is higher which promotes void growth. In addition, the strain state strongly differs from plane strain conditions thus delaying localization (Needleman and Rice, 1978; Besson et al., 2001c). These two factors lead to internal necking between primary cavities. Shear bands are avoided and secondary dimples are not observed.

Simulation of flat to slant transition remains a difficult task. It was first performed in Mathur et al. (1996) in the case of dynamic crack growth but no attempt was made to compare results with actual tests. The transition was also modeled in Besson et al. (2001a) but matching simultaneously crack paths and load-displacement curves was not possible. More recently 
the flat to slant transition was obtained in Xue, (2007) and Xue and Wierzbicki (2008) using an explicit FE simulation but comparison with experiments was also missing.

Flat to slant transition in sheets therefore raises several questions and outlines the needs for research efforts in the field of ductile rupture:

- Slant fracture occurs at relatively low stress triaxiality. Models such as the GTN model, are representative of damage growth a high stress triaxiality where void growth is the controlling damage mechanism. Low triaxiality rupture was recently studied (Bao and Wierzbicki, 2004; Barsoum and Faleskog, 2007a,b; Xue, 2007). In particular, it was shown that depending on the material, ductility may decrease when stress triaxiality decreases from $1 / 3$ (pure tension) to 0 (pure shear) (Bao and Wierzbicki, 2004; Barsoum and Faleskog, 2007a). These studies also outlined the role of the Lode parameter on ductility (Xue, 2007; Zhang et al., 2001). The GTN model was recently modified to introduce a softening term depending on the Lode parameter (Nahshon and Hutchinson, 2008).

- The question of the origin of the localization band corresponding to "void sheeting' can be raised. Does localization occur first so that the second population is nucleated within the band or does nucleation of a second population trigger localization. As the second cavity population associated with the 'void sheeting' mechanism is in most cases not seen outside of the localization band, the first explanation seems correct. However, secondary nucleation is not easy to detect so that the question remains open. Models recently proposed (Nahshon and Hutchinson, 2008; Fabrégue and Pardoen, 2008) correspond to the second hypothesis.

- As two populations are involved, the material has obviously at least two characteristic length scales. If a nonlocal model is to be used, this would imply to use two different nonlocal variables each being associated with a particular length. As the characteristic length associated to the second population is very small (about $1 \mu \mathrm{m}$ ) this would lead to huge FE simulations.

- The previous remark also clearly outlines that computational strategies have to be developed. These strategies, within the context of CDM, should meet the following requirements: (i) Calculations have to be 3D. (ii) Crack path should not be known a priori. (iii) Simulations should be mesh (size and element type) independent. (iv) Remeshing and parallel computations should be used to allow for large crack extension while keeping fine elements to properly represent crack tip fields. 


\section{REFERENCES}

Abouaf, M., Chenot, J.L., Raisson, G. and Baudouin, P. (1988). Finite Element Simulation of Hot Isostatic Pressing of Metal Powders, Int. J. Numer. Meth. Eng., 25(1): 191-212.

Aifantis, E. (1987). The Physics of Plastic Deformation. Int. J. Plasticity, 3: 211-248.

Anand, L., Kim, K.H. and Shawki, T.G. (1987). Onset of Shear Localization in Viscoplastic Solids, J. Mech. Phys. Solids, 35(4): 407-429.

Andrade Pires, F.M, César de Sa, J.M.A., Costa Sousa, L. and Natal Jorge, R.M. (2003). Numerical Modelling of Ductile Plastic Damage in Bulk Metal Forming, Int. J. Mech. Sci., 45(2): 273-294.

Aravas, A. and Ponte Castañeda, P. (2004). Numerical Methods for Porous Metals with Deformation-induced Anisotropy, Comp. Meth. Appl. Mech. Eng., 193(36-38): 3767-3805.

Aravas, N. (1987). On the Numerical Integration of a Class of Pressure-dependent Plasticity Models, Int. J. Numer. Meth. Eng., 24: 1395-1416.

Argon, A.S., Im, J. and Safoglu, R., (1975). Cavity Formation From Inclusions in Ductile Fracture, Met. Trans., 6A: 825-837.

Armero, F. and Oller, S. (2000). A General Framework for Continuum Damage Models. II. Integration Algorithms with Applications to the Numerical Simulation of Porous Metals, Int. J. Solids Structures, 37(48-50): 7437-7464.

Arndt, S., Svendsen, B. and Klingbeil, D. (1997). Modellierung Der Eigenspannungen and Der Rißspitze Mit Einem Schägigungsmodell, Technische Mechanik, 17(4): 323-332.

ASTM-B871. (2001). Standard B871-01.2001, Technical report, ASTM International, Ecole des Mines de Paris.

Aubry, D., Jay, G., Tie, B. and Muzzolini, R. (2003). A Combined Mesh and Model Adaptive Strategy for the Scaling Issues in the Numerical Modelling of the Ductile Damage in Thin Panels, Comp. Meth. Appl. Mech. Eng., 192(28-30): 3285-3300.

Babout, L., Maire, E., Buffiére, J.Y. and Fougéres, R. (2001). Characterization by X-ray Computed Tomography of Decohesion Porosity Growth and Coalescence in Model Metal Matrix Composites, Acta Mater., 49: 2055-2063.

Bandstra, J.P. and Koss, D.A. (2008). On the Influence of Void Clusters on Void Growth and Coalescence During Ductile Failure, Acta Mater., 56: 4429-4439.

Bao, Y. and Treitler, R. (2004). Ductile Crack Formation on Notched Al2024-T351 Bars Under Compression Tension Loading, Mater. Sci. Eng., A 384: 385-394.

Bao, Y. and Wierzbicki, T. (2004). On Fracture Locus in the Equivalent Strain and Stress Triaxiality Space, Int. J. Mech. Sci., 46(1): 81-98.

Barbier, G., Benallal, A. and Cano, V. (1998). Relation Théorique Entre la Méthode de Perturbation Linéaire et l'analyse de Bifurcation Pour la Prédiction de la Localisation Des Déformations, C. R. Acad. Sci. Paris, 326(3): 153-158.

Bargellini, R., Besson, J., Lorentz, E. and Michel-Ponnelle, S. (2007). A Nonlocal Finite Element Based on Volumetric Strain Gradient: Application to Ductile Fracture, Comput. Mat. Sci., Available Online at: http://www.sciencedirect.com.gate6.inist.fr/science?

Barlat, F., Lege, D.J. and Brem, J.C. (1991). A Six-Component Yield Function for Anisotropic Materials, Int. J. Plasticity, 7: 693-712.

Barsoum, I. and Faleskog, J. (2007a). Rupture Mechanisms in Combined Tension and Shear Experiments, Int. J. Solids Structures, 44(6): 1768-1786.

Barsoum, I. and Faleskog, J. (2007b). Rupture Mechanisms in Combined Tension and ShearMicromechanics, Int. J. Solids Structures, 44(17): 5481-5498.

Bazant, Z.P. and Pijaudier-Cabot, G. (1988). Non Local Continuum Damage. Localization, Instability and Convergence, J. Applied Mech., 55: 287-294. 
Becker, R., Smelser, R.E. and Richmond, O. (1989). The Effect of Void Shape on the Development of Damage and Fracture in Plane Strain Tension, J. Mech. Phys. Solids, 37: 111-129.

Benzerga, A. (2000). Rupture d'aciers Pour Gazoducs. Ph.D. Thesis, Ecole des Mines de Paris.

Benzerga, A.A. and Besson, J. (2001). Plastic Potentials for Anisotropic Porous Solids, Eur. J. Mech., 20A(3): 397-434.

Benzerga, A., Besson, J. and Pineau, A. (1999). Coalescence-controlled Anisotropic Ductile Fracture, J. Eng. Mater. Technol., 121: 121-229.

Berdin, C., Besson, J., Bugat, S., Desmorat, R., Feyel, F., Forest, S., Lorentz, E., Maire, E., Pardoen, T., Pineau, A. and Tanguy, B. (2004), Local Approach To Fracture, Presses de l'Ecole des Mines, (Paris).

Beremin, F.M., (1981). Cavity Formation From Inclusions in Ductile Fracture of A508 Steel, Met. Trans., 12A: 723-731.

Berveiller, M. and Zaoui, A. (1978). An Extension of the Self-consistent Scheme to Plastically Flowing Polycrystals, J. Mech. Phys. Solids, 26: 325-344.

Besson, J., Brocks, W., Chabanet, O. and Steglich, D. (2001a). Ductile Rupture of Aluminum Sheet Materials, European Journal of Finite Elements, 10: 401-415.

Besson, J., Cailletaud, G., Chaboche, J.-L. and Forest, S. (2001b), Mécanique non-linéaire des matériaux. Hermes.

Besson, J., Devillers-Guerville, L, and Pineau, A. (2000). Modeling of Scatter and Size Effect in Ductile Fracture: Application to Thermal Embrittlement of Duplex Stainless Steels, Eng. Fract. Mech., 67(2): 169-190.

Besson, J. and Guillemer-Neel, C. (2003). An Extension of the Green and Gurson Models to Kinematic Hardening, Mechan. of Mater., 35: 1-18.

Besson, J., Steglich, D. and Brocks, W. (2001c). Modeling of Crack Growth in Round Bars and Plane Strain Specimens, Int. J. Solids Structures 38(46-47): 8259-8284.

Besson, J., Steglich, D. and Brocks, W. (2003). Modeling of Plane Strain Ductile Rupture, Int. J. Plasticity, 19(10): 1517-1541.

Billardon, R. and Doghri, I. (1989). Prediction of Macro-Crack Initiation By Damage Localization, C. R. Acad. Sci. Paris, 308(Série II): 347-352.

Blazy, S., Marie-Louise, A., Forest, S., Chastel, Y., Pineau, A., Awade, A., Grolleron, C. and Moussy, F. (2004). Deformation and Fracture of Aluminium Foams Under Proportional and Non Proportional Multi-Axial Loading: Statistical Analysis and Size Effect, Int. J. Mech. Sci., 46(2): 217-244.

Bonnenfant, D., Mazerolle, F. and Suquet, P. (1998). Compaction of Powders Containing Hard Inclusions: Experiments and Micromechanical Modeling, Mech. of Mater., 29: 93-109.

Bonora, N. (1997). A Nonlinear CDM Model for Ductile Failure, Eng. Fract. Mech., 58(1-2): $11-28$.

Bonora, N. and Milella, P.P. (2001). Constitutive Modeling for Ductile Metals Behavior Incorporating Strain Rate, Temperature and Damage Mechanics, Int. J. Impact Eng., 26(1-10): 53-64.

Bordreuil, C., Boyer, J.C. and Sallé, E. (2003). On Modelling the Growth and the Orientation Changes of Ellipsoidal Voids in a Rigid Plastic Matrix, Modelling Simul. Mater. Sci. Eng., 11(3): $365-380$.

Borouchaki, H., Laug, P., Cherouat, A. and Saanouni, K. (2005). Adaptive Remeshing in Large Plastic Strain With Damage, Int. J. Numer. Meth. Eng., 63(1): 1-36.

Borré, G. and Maier, G. (1989). On Linear Versus Nonlinear Flow Rules in Strain Localization Analysis, Meccanica, 24: 36-41.

Bouchard, P.O., Bay, F., Chastel, Y. and Tovena, I. (2000). Crack Propagation Modelling Using an Advanced Remeshing Technique, Comp. Meth. Appl. Mech. Eng., 189: 723-742.

Brocks, W., Sun, D. Z. and Hönig, A. (1995). Verification of the Transferability of Micromechanical Parameters By Cell Model Calculations With Visco-Plastic Materials, Int. J. Plasticity, 11: 971-989. 
Brokken, D., Brekelmans, W.A.M. and Baaijens, F.P.T. (2000). Predicting the Shape of Blanked Products: A Finite Element Approach, J. Mater. Processing Technol., 103: 51-56.

Bron, F. (2004). DÕchirure Ductile Des Tles Minces En Alliage D'aluminium 2024 Pour Application AÕronautique. Ph.D. Thesis, Ecole des Mines de Paris.

Bron, F. and Besson, J. (2004). A Yield Function for Anisotropic Materials. Application to aluminium alloys, Int. J. Plasticity, 20: 937-963.

Bron, F. and Besson, J. (2006). Simulation of the Ductile Tearing for Two Grades of 2024 Aluminum Alloy Thin Sheets, Eng. Fract. Mech., 73: 1531-1552.

Bron, F., Besson, J. and Pineau, A. (2004). Ductile Rupture in Thin Sheets of Two Grades of 2024 Aluminum Alloy, Mater. Sci. Eng., A 380: 356-364.

Brown, L.M. and Embury, J.D. (1973). The Initiation and Growth of Voids at Second Phase Particles, In: Proc. Third Int. Conf. on the Strength of Metals and Alloys, ICSMA 3, Cambridge, UK.

Brunet, M. and Morestin, F. (2001). Experimental and Analytical Necking Studies of Anisotropic Sheet Metals, J. Mater. Processing Technol, 112: 214-226.

Brunet, M., Morestin, F. and Walter-Leberre, H. (2005). Failure Analysis of Anisotropic SheetMetals Using a Non-local Plastic Damage Model, J. Mater. Processing Technol., 170: 457-470.

Budianski, B., Hutchinson, J.W. and Slutsky, S. (1982), Mechanics of Solids - the Rodney Hill 60th Anniversary Volume. Pergamon, Ch. Void Growth and Collapse in Viscous Solids, pp. 13-45.

Castagne, S., Habraken, A.M. and Cescotto, S. (2003). Application of a Damage Model to an Aluminum Alloy, Int. J. Damage Mech., 12: 5-30.

Chaboche, J.L. (1981). Continuous Damage Mechanics: A Tool to Describe Phenomena Before Crack Initiation, Nucl. Eng. Design, 64: 233-247.

Chaboche, J.L. (1993). Development of Continuum Damage Mechanics for Elastic Solids Sustaining Anisotropic and Unilateral Damage, Int. J. Damage Mech., 2: 311-329.

Chaboche, J.L. (2008). A Review of Some Plasticity and Viscoplasticity Constitutive Theories, Int. J. Plasticity, 24: 1642-1693.

Chaboche, J.L., Boudifa, M. and Saanouni, K. (2006). A CDM Approach of Ductile Damage With Plastic Compressibility, Int. J. Frac., 137(1-4): 51-75.

Cherouat, A., Saanouni, HK. and Hammi, Y. (2002). Numerical Improvement of Thin Tubes Hydroforming with Respect to Ductile Damage, Int. J. Mech. Sci., 44: 2427-2446.

Chow, C.L. and Wang, J. (1987). An Anisotropic Theory of Continuum Damage Mechanics for Ductile Fracture, Eng. Fract. Mech., 27(5): 547-558.

Chow, C.L. and Wang, J. (1988a). Ductile Fracture Characterization With an Anisotropic Continuum Damage Theory, Eng. Fract. Mech., 30(5): 547-563.

Chow, C.L. and Wang, J. (1988b). A Finite Element Analysis of Continuum Damage Mechanics for Ductile Fracture, Int. J. Frac., 38: 83-102.

Chu, C.C. and Needleman, A. (1980). Void Nucleation Effects in Biaxially Stretched Sheets, J. Eng. Mater. Technol., 102: 249-256.

Cordebois, J.P. and Sidoroff, F. (1982). Endommagement anisotrope en élasticité et plasticité, J. Méca. Théo. et Appliquée Numéro spécial, 45-60.

Cornec, A., Scheider, I. and Schwalbe, K.H. (2003). On the Practical Application of the Cohesive Model, Eng. Fract. Mech., 70(14): 1963-(1987).

Cosserat, E. and Cosserat, F. (1909), Théorie des corps déformables, Hermann et Fils.

Dawicke, D.S., Piascik, R.S. and Newman Jr, J.C. (1997). Prediction of Stable Tearing and Fracture of a 2000 Series Aluminium Alloy Plate Using a CTOA Criterion, In: Piascik, R.S., Newman, J.C. and Dowlings, N.E. (eds), Fatigue and Fracture Mechanics, Vol. 27, ASTM STP 1296, ASTM, pp. 90-104.

De Borst, R. (1991). Simulation of Strain Localization: A Reappraisal of the Cosserat Continuum, Eng. Comput., 8: 317-332. 
Desmorat, R. and Cantournet, S. (2008). Modeling Microdefects Closure Effect with Isotropic/ Anisotropic Damage, Int. J. Damage Mech., 17(1): 65-96.

Doege, E., El-Dsoki, T. and Seibert, D. (1995). Prediction of Necking and Wrinkling in Sheetmetal Forming, J. Mat. Proc. Tech., 50: 197-206.

Doghri, I. (1995). Numerical Implementation and Analysis of a Class of Metal Plasticity Models Coupled with Ductile Damage, Int. J. Numer. Meth. Eng., 38(20): 3403-3431.

Enakoutsa, K., Leblond, J.B. and Perrin, G. (2007). Numerical Implementation and Assessment of a Phenomenological Nonlocal Model of Ductile Rupture, Comp. Meth. Appl. Mech. Eng., 196(13-16): 1946-1957.

Enami, K. (2005). The Effects of Compressive and Tensile Prestrain on Ductile Fracture Initiation in Steels, Eng. Fract. Mech., 72(7): 1089-1105.

Eringen, A.C. (1990). Theory of Thermo-microstretch Elastic Solids, Int. J. Eng. Sci., 28(12): 1291-1301.

Eringen, A.C. and Edelen, D.G.B. (1966). On Nonlocal Elasticity, Int. J. Eng. Sci., 10: 233-248.

Eringen, A. and Suhubi, E. (1964). Nonlinear Theory of Simple Microelastic Solids, Int. J. Eng. Sci. 2: 189-203.

Eshelby, J.D., (1957). The Determination of the Elastic Field of an Ellipsoidal Inclusion, and Related Problems, Proc. Roy. Soc, A. 241: 357-396.

Fabrégue, D. and Pardoen, T. (2008). A Constitutive Model for Elastoplastic Solids Containing Primary and Secondary Voids, J. Mech. Phys. Solids, 56: 719-741.

Faleskog, J., Gao, X. and Shih, C.F. (1998). Cell model for nonlinear fracture analysis - I Micromechanics calibration, Int. J. Frac., 89: 355-373.

Fleck, N., Kuhn, L.T. and McMeecking, R.M. (1992). Yielding of Metal Powder Bonded by Isolated Contacts, J. Mech. Phys. Solids, 40(5): 1139-1162.

Forest, S., Barbe, F. and Cailletaud, G. (2000). Cosserat Modelling of Size Effects in the Mechanical Behaviour of Polycrystals and Multi-phase Materials, Int. J. Solids Structures, 37(46-47): 7105-7126.

Forest, S. and Sievert, R. (2006). Nonlinear Microstrain Theories, Int. J. Solids Structures, 43: 7224-7245.

Fressengeas, C. and Molinari, A. (1985). Inertia and Thermal Effects on the Localization of Plastic Flow, Acta Metall., 33(3): 387-396.

Gaffard, V., Besson, J. and Gourgues-Lorenzon, A.F. (2005). Creep Failure Model of a Tempered Martensitic Stainless Steel Integrating Multiple Deformation and Damage Mechanisms, Int. J. Frac., 133(2): 139-166.

Garrison, W.M. and Moody, N.R. (1987). Ductile Fracture, J. Phys. Chem. Solids, 48(11): $1035-1074$.

Germain, N., Besson, J. and Feyel, F. (2007). Composite Layered Materials: Anisotropic Nonlocal Damage Models, Comp. Meth. Appl. Mech. Eng., 196(41-44): 4272-4282.

Germain, P., Nguyen, Q.S. and Suquet, P. (1983). Continuum Thermodynamics, J. Applied Mech., 5: 1010-1020.

Gologanu, M., Leblond, J.B. and Devaux, J. (1993). Approximate Models for Ductile Metals Containing Non-spherical Voids-Case of Axisymmetric Prolate Ellipsoidal Cavities, J. Mech. Phys. Solids, 41(11): 1723-1754.

Gologanu, M., Leblond, J.B. and Devaux, J. (1994). Approximate Models for Ductile Metals Containing Non-Spherical Voids - Case of Axisymmetric Oblate Ellipsoidal Cavities, J. Eng. Mater. Technol., 116: 290-297.

Gologanu, M., Leblond, J.B., Perrin, G. and Devaux, J. (1997). Recent Extensions of Gurson's Model for Porous Ductile Metals. In: Suquet, P. (ed.), Continuum Micromechanics, CISM Lectures Series. New York, Springer, pp. 61-130.

Goods, S.H. and Brown, L.M. (1979). The Nucleation of Cavities by Plastic Deformation, Acta Metall., 27: 1-15. 
Grange, M., Besson, J. and Andrieu, E. (2000a). An Anisotropic Gurson Model to Represent the Ductile Rupture of Hydrided Zircaloy-4 Sheets, Int. J. Frac., 105(3): 273-293.

Grange, M., Besson, J. and Andrieu, E. (2000b). Anisotropic Behavior and Rupture of Hydrided Zircaloy-4 Sheets, Met. Mater. Trans., 31A: 679-690.

Green, R.J. (1972). A Plasticity Theory for Porous Solids, Int. J. Mech. Sci, 14: 215-224.

Guillemer-Neel, C., Feaugas, X. and Clavel, M. (2000a). Mechanical Behavior and Damage Kinetics in Nodular Cast Iron: Part I. Damage Mechanisms, Met. Mater. Trans., 31A: 3063-3074.

Guillemer-Neel, C., Feaugas, X. and Clavel, M. (2000b). Mechanical Behavior and Damage Kinetics in Nodular Cast Iron: Part II. hardening and damage, Met. Mater. Trans., 31A: 3075-3085.

Gurson, A.L. (1977). Continuum Theory of Ductile Rupture by Void Nucleation and Growth: Part I- Yield Criteria and Flow Rules for Porous Ductile Media, J. Eng. Mater. Technol., 99: 2-15.

Hahn, G.T. and Rosenfield, A.R. (1975). Metallurgical Factors Affecting Fracture Toughness of Aluminum Alloys, Met. Trans., 6A(4): 653-668.

Halm, D. and Dragon, A. (1998). An Anisotropic Model of Damage and Frictional Sliding for Brittle Materials, Eur. J. Mech., 17A(3): 439-460.

Hammi, Y., Bammann, D.J. and Horstemeyer, M.F. (2004). Modeling of Anisotropic Damage for Ductile Materials in Metal Forming Processes, Int. J. Damage Mech., 14(4): 123-146.

Hammi, Y. and Horstemeyer, M.F. (2007). A Physically Motivated Anisotropic Tensorial Representation of Damage with Separate Functions for Void Nucleation, Growth, and Coalescence, Int. J. Plasticity, 23: 1641-1678.

Hill, R. (1950), The Mathematical Theory of Plasticity. Oxford, Clarendon Press.

Huang, Y. (1991). Accurate Dilatation Rates for Spherical Voids in Triaxial Stress Fields, J. Applied Mech., 58: 1084-1086.

Hughes, T.J.R. (1980). Generalization of Selective Integration Procedures to Anisotropic and Non Linear Media, Int. J. Numer. Meth. Eng., 15: 1413-1418.

James, M.A. and Newman, J.C. (2003). The Effect of Crack Tunneling on Crack Growth: Experiments and CTOA Analyses, Eng. Fract. Mech., 70: 457-468.

Ju, J.W. (1989). On Energy-based Coupled Elastoplastic Damage Theories: Constitutive Modeling and Computational Aspects, Int. J. Solids Structures, 25(7): 803-833.

Kachanov, L.M. (1958). Time of the Rupture Process Under Creep Conditions, Isv. Akad. Nauk. SSR. Otd Tekh. Nauk., 8: 26-31.

Kailasam, M., Aravas, N. and Ponte Castañeda, P. (2000). Porous Metals With Developing Anisotropy: Constitutive Models, Computational Issues and Applications To Deformation Processing, Comput. Model. Engrg Sci., 1(2): 105-118.

Kailasam, M. and Ponte Castañeda, P. (1998). A General Constitutive Theory for Linear and Nonlinear Particulate Media with Microstructure Evolution, J. Mech. Phys. Solids, 46(3): $427-465$.

Karafillis, A.P. and Boyce, M.C. (1993). A General Anisotropic Yield Criterion Using Bounds and a Transformation Weighting Tensor, J. Mech. Phys. Solids, 41: 1859-1886.

Kim, A.S., Besson, J. and Pineau, A. (1999). Global and Local Approaches to Fracture Normal To Interfaces, Int. J. Solids Structures, 36: 1845-1864.

Kim, A.S., Suresh, S. and Shih, C.F. (1997). Plasticity Effects on Fracture Normal to Interfaces With Homogeneous and Graded Compositions, Int. J. Solids Structures, 34(26): 3415-3432.

Kim, J. and Gao, X. (2005). A Generalized Approach to Formulate the Consistent Tangent Stiffness in Plasticity with Application to the GLD Porous Material Model, Int. J. Solids Structures, 42(1): 103-122.

Koplik, J. and Needleman, A. (1988). Void Growth and Coalescence in Porous Plastic Solids, Int. J. Solids Structures, 24(8): 835-853. 
Krajcinovic, D. (1985). Continuous Damage Mechanics Revisited: Basic Concepts and Definitions, J. Appl. Mech., 52: 829-834.

Krajcinovic, D. (1996), Damage Mechanics., Elsevier.

Kröner, E. (1967). Elasticity Theory of Materials With Long Range Cohesive Forces, Int. J. Solids Structures, 3: 731-742.

Kuna, M. and Sun, D.Z. (1996). Three-dimensional Cell Model Analyses of Void Growth in Ductile Materials, Int. J. Frac., 81: 235-258.

Leblond, J.B., Perrin, G. and Devaux, J. (1995). An Improved Gurson-type Model for Hardenable Ductile Metals, Eur. J. Mech., 14A(4): 499-527.

Leblond, J.B., Perrin, G. and Suquet, P. (1994). Exact Results and Approximate Models for Porous Viscoplastic Solids, Int. J. Plasticity, 10(3): 213-235.

Lee, B.J. and Mear, M.E. (1999). Stress Concentration Induced by an Elastic Spheroidal Particle in a Plastically Deforming Solid, J. Mech. Phys. Solids, 47(6): 1301-1336.

Lemaitre, J. (1985). A Continuous Damage Mechanics Model for Ductile Fracture, J. Eng. Mater. Technol., 107: 83-89.

Lemaitre, J. (1996), A Course on Damage Mechanics, Springer.

Lemaitre, J. and Chaboche, J.L. (1990), Mechanics of Solid Materials., Cambridge University Press, Cambridge, UK.

Lemaitre, J. and Desmorat, R. (2005), Engineering Damage Mechanics, Springer.

Lemaitre, J., Desmorat, R. and Sausay, M. (2000). Anisotropic Damage Laws of Evolution, Eur. J. Mech., 19A: 187-208.

Liu, Y., Murakami, S. and Kanagawa, Y. (1994). Mesh-dependence and Stress Singularity in Finite Element Analysis of Creep Crack Growth by Continuum Damage Mechanics Approach, Eur. J. Mech., 13A(3): 395-417.

Lorentz, E. and Andrieux, S. (2003). Analysis of Non-local Models Through Energetic Formulations, Int. J. Solids Structures, 40: 2905-2936.

Luu, T.T. (2006). Déchirure Ductile Des Aciers â Haute Résistance Pour Gazoducs (X100). Ph.D. Thesis, Ecole des Mines de Paris.

Mahmoud, S. and Lease, K. (2003). The Effect of Specimen Thickness On the Experimental Caracterisation of Critical Crack Tip Opening Angle in 2024-T351 aluminum alloy, Eng. Fract. Mech., 70: 443-456.

Mahnken, R. (1999). Aspects on the Finite-element Implementation of the GUrson Model Including Parameter Identification, Int. J. Plasticity, 15: 1111-1137.

Maire, E., Bordreuil, C., Babout, L. and Boyer, J.C. (2005). Damage Initiation and Growth in Metals. Comparison Between Modelling and Tomography Experiments, J. Mech. Phys. Solids, 53: 2411-2434.

Maire, E., Buffière, J.Y., Salvo, L., Blandin, J.J., Ludwig, W. and Letang, J.M. (2001). On the Application of X-Ray Microtomography in the Field of Materials Science, Advan. Eng. Mater., 3(8): 539-546.

Marini, B., Mudry, F. and Pineau, A. (1985). Experimental Study of Cavity Growth in Ductile Rupture, Eng. Fract. Mech., 22(6): 989-996.

Mathur, K.K., Needleman, A. and Tvergaard, V. (1996). Three Dimensional Analysis of Dynamic Ductile Crack Growth in a Thin Plate, J. Mech. Phys. Solids, 44(3): 439-464.

Mc Clintock, F.A. (1968). A Criterion for Ductile Fracture by the Growth of Holes, J. App. Mech., 35: 363-371.

Mear, M.E. and Hutchinson, J.W. (1985). Influence of Yield Surface Curvature on Flow Localization In Dilatant Plasticity, Mech. Mat., 4: 395-407.

Mediavilla, J., Peerlings, R.H.J. and Geers, M.G.D. (2006). Discrete Crack Modelling of Ductile Fracture Driven by Non-local Softening Plasticity, Int. J. Numer. Meth. Eng., 66(4): 661-688. 
Mediavilla, J., Peerlings, R.H.J. and Geers, M.G.D. (2006b). A Robust and Consistent Remeshing-Transfer Operator for Ductile Fracture Simulations, Comp. \& Struct., 84(8-9): 604-623.

Michel, J.C., Moulinec, H. and Suquet, P. (2001). A Computational Scheme for Linear and Non-Linear Composites With Arbitrary Phase Contrast, Int. J. Numer. Meth. Eng., 52(1-2): 139-158.

Michel, J.C. and Suquet, P. (1992). The Constitutive Law of Nonlinear Viscous and Porous Materials, J. Mech. Phys. Solids, 40: 783-812.

Mindlin, R. and Eshel, N. (1968). On the First Strain Gradient Theories in Linear Elasticity, Int. J. Solids Structures, 4: 109-124.

Moes, N. and Belytschko, T. (2002). Extended Finite Element Method for Cohesive Crack Growth, Eng. Fract. Mech., 69(7): 813-833.

Monchiet, V., Cazacu, O., Charkaluk, E. and Kondo, D. (2008). Macroscopic Yield Criteria for Plastic Anisotropic Materials Containing Spheroidal Voids, Int. J. Plasticity, 24: 1158-1189.

Monchiet, V., Gruescu, C., Charkaluk, E. and Kondo, D. (2006). Approximate Yield Criteria for Anisotropic Metals With Prolate or Oblate Voids, C. R. Mécanique 334(7): 431-439.

Morgeneyer, T.F., Starink, M.J. and Sinclair, I. (2008). Evolution of Voids During Ductile Crack Propagation in an Aluminium Alloy Sheet Toughness Test Studied By Synchrotron Radiation Computed Tomography, Acta Mater., 56: 1671-1679.

Murakami, S. (1983). Notion of Continuum Damage Mechanics and its Application to Anisotropic Creep Damage Theory, J. Eng. Mater. Technol., 105(2): 99-105.

Nahshon, K. and Hutchinson, J.W. (2008). Modification of the Gurson Model for Shear Failure, Eur. J. Mech., 27A: 1-17.

Needleman, A. (1987). A Continuum Model for Void Nucleation by Inclusion Debonding, J. Applied Mech., 54: 525-531.

Needleman, A. (1990). An Analysis of Tensile Decohesion Along an Interface, J. Mech. Phys. Solids, 38: 289-324.

Needleman, A. and Rice, J.R. (1978). Limits to Ductility Set by Plastic Flow Localization. In: D.P. Koistinen, et al. (Eds), Mechanics of Sheet Metal Forming. Plenum Publishing, pp. 237-267.

O’Dowd, N.P. and Shih, C.F. (1991). Family of Crack-tip Fields Characterized by a Triaxiality Parameter-I. Structure of Fields, J. Mech. Phys. Solids, 39(8): 989-1015.

O'Dowd, N.P. and Shih, C.F. (1992). Family of Crack-tip Fields Characterized by a Triaxiality Parameter-II. Fracture applications, J. Mech. Phys. Solids, 40(8): 939-963.

Ortiz, M. and Quigley, J.J. (1991). Adaptive Mesh Refinement in Strain Localization Problems, Comp. Meth. Appl. Mech. Eng., 90: 781-804.

Pardoen, T. and Hutchinson, J.W. (2000). An Extended Model for Void Growth and Coalescence, J. Mech. Phys. Solids, 48(12): 2467-2512.

Pardoen, T. and Hutchinson, J.W. (2003). Micromechanics-based Model for Trends in Toughness of Ductile Metals, Acta Mater., 51: 133-148.

Pastor, J., Francescato, P., Trillat, M., Loute, E. and Rousselier, G. (2004). Ductile failure of Cylindrically Porous Materials. Part II: Other Cases of Symmetry, Eur. J. Mech., 23A(2): 191-201.

Peerlings, R.H.J., De Borst, R., Brekelmans, W.A.M., De Vree, J.H.P. and Spee, I. (1996). Some Observations on Localisation In Non-local and Gradient Damage Models, Eur. J. Mech., 15A(6).

Pineau, A. (1980). Review of Fracture Micromechanisms and a Local Approach to Predicting Crack Resistance In Low Strength Steels. In: Proc. ICF 5 Conference, Vol. 2, Cannes (France).

Pineau, A. (2006). Development of the Local Approach to Fracture Over the Past 25 Years: Theory and Applications, Int. J. Frac., 138(1-4): 139-166. 
Ponte Castañeda, P. and Suquet, P. (1998). Nonlinear Composites, Adv. in Appl. Mech., 34: 171-302.

Ponte-Castañeda, P. and Zaidman, M. (1994). Constitutive Models for Porous Materials with Evolving Microstructure, J. Mech. Phys. Solids, 42: 1459-1495.

Prat, F., Grange, M., Besson, J. and Andrieu, E. (1998). Behavior and Rupture of Hydrided Zircaloy-4 Tubes and Sheets, Met. Mater. Trans., 29A: 1643-1651.

Reusch, F., Svendsen, B. and Klingbeil, D. (2003). Local and Non-local Gurson-based Ductile Damage and Failure Modelling at Large Deformation, Eur. J. Mech., 22A: 779-792.

Rice, J.R. (1968). A Path Independent Integral and the Approximate Analysis of Strain Concentration By Notched and Cracks, J. Applied Mech., 35: 379.

Rice, J.R. (1976). The Localisation of Plastic Deformation. In: Koiter, W.T. (ed.), Proc. 14th Int. Conf. Theoretical and Applied Mechanics, Delft. North-Holland, Amsterdam.

Rice, J.R. (1980). The Mechanics of Earthquake Rupture, Proceedings of the International School of Physics 'Enrico Fermi'. North-Holland, pp. 555-649.

Rice, J.R. and Tracey, D.M. (1969). On the Ductile Enlargement of Voids in Triaxial Stress Fields, J. Mech. Phys. Solids, 17: 201-217.

Riks, E. (1979). An Incremental Approach to the Solution of Snapping and Buckling Problems, Int. J. Solids Structures, 15: 529-551.

Ristinmaa, M. (1997). Void Growth in Cyclic Loaded Porous Plastic Solid, Mech. Mater., 26: $227-245$.

Ritchie, R.O., Knott, J.F. and Rice, J.R. (1973). On the Relationship Between Critical Tensile Stress and Fracture Toughness in Mild Steel, J. Mech. Phys. Solids, 21: 395-410.

Rivalin, F., Besson, J., Di Fant, M. and Pineau, A. (2000). Ductile Tearing of Pipeline-steel Wide Plates - II: Modeling of in-plane Crack Propagation, Eng. Fract. Mech., 68(3): 347-364.

Rousselier, G. (1987). Ductile Fracture Models and Their Potential in Local Approach of Fracture, Nucl. Eng. Design, 105: 97-111.

Rousselier, G. (1991). Application de l'analyse de Stabilité d'une Perturbation à la Localisation de la Déformation Dans un Matériau Dilatable Adoucissant., C. R. Acad. Sci. Paris, 313 (Série II): 1367-1373.

Rousselier, G. (1995). Stabilité Locale et Modes de Rupture Ductile., C. R. Acad. Sci. Paris, 320(Série IIb): 69-75.

Rousselier, G. (2001). Dissipation in Porous Metal Plasticity and Ductile Fracture, J. Mech. Phys. Solids, 49: 1727-1746.

Rousselier, G. and Leclercq, S. (2006). A Simplified "polycrystalline" Model for Viscoplastic and Damage Finite Element Analyses, Int. J. Plasticity, 22: 685-712.

Roychowdhury, Y.D.A. and Dodds Jr, R.H. (2002). Ductile Tearing in thin Aluminum Panels: Experiments and Analyses using Large-displacement, 3-D Surface Cohesive Elements, Eng. Fract. Mech., 69: 983-1002.

Rudnicki, J.W. and Rice, J.R. (1975). Conditions for the Localization of Deformation in Pressure-Sensitive Dilatant Materials, J. Mech. Phys. Solids, 23: 371-394.

Ruggieri, C. and Dodds, R.H (1996). A Tranferability Model for Brittle Fracture Including Constraint and Ductile Tearing Effects: a Probabilistic Approach, Int. J. Frac., 79: 309-340.

Saanouni, K. (2006). Virtual Metal Forming Including the Ductile Damage Occurrence Actual State of the Art and Main Perspectives, J. Mater. Processing Technol 177: 19-25.

Saanouni, K., Chaboche, J.L. and Lesne, P.M. (1989). On the Creep Crack Growth Prediction By a Non Local Damage Formulation, Eur. J. Mech., 8A(6): 437-459.

Sainte Catherine, C., Poussard, C., Vodinh, J., Schill, R., Hourdequin, N., Galon, P. and Forget, P. (2002). Finite Element Simulations and Empirical Correlation for Charpy-V and sub-size Charpy Tests on an Unirradiated low Alloy RPV Ferritic Steel. In: Fourth symposium on small specimen test techniques, Reno, Nevada, ASTM STP 1418. 
Scheider, I. and W., Brocks (2003). Simulation of Cup-cone Fracture Using the Cohesive Model, Eng. Fract. Mech., 70(14): 1943-1961.

Segurado, J. and Llorca, J. (2004). A New Three-Dimensional Interface Finite Element to Simulate Fracture in Composites, Int. J. Solids Struct., 41(11-12): 2977-2993.

Shima, S. and Oyane, M. (1976). Plasticity Theory for Porous Metals, Int. J. Mech. Sci., 18: $285-291$.

Sidoroff, F. and Dogui, A. (2001). Some Issues About Anisotropic Elastic-Plastic Models at Finite Strain, Int. J. Solids Struct., 38: 9569-9578.

Siegmund, T. and Brocks, W. (1999). Prediction of the Work of Separation and Implications to Modelling, Int. J. Frac., 99: 97-116.

Simo, J.C. (1992). Algorithms for Static and Dynamic Multiplicative Plasticity that Preserve the Classical Return Mapping Schemes of the Infinitesimal Theory, Comp. Meth. Appl. Mech. Eng., 99(1): 61-112.

Simo, J.C. and Miehe, C. (1992). Associative Coupled Thermoplasticity at Finite Strains Formulation, Numerical-Analysis and Implementation, Comp. Meth. Appl. Mech. Eng., 98(1): 41-104.

Simo, J.C. and Taylor, R.L. (1985). Consistent Tangent Operators for Rate-independent Elastoplasticity, Comp. Meth. Appl. Mech. Eng., 48: 101-118.

Simo, J.C., Taylor, R.L. and Pister, K.S. (1985). Variational and Projection Methods for the Volume Constraint in Finite Deformation Elastoplasticity, Comp. Meth. Appl. Mech. Eng., 51: 177-208.

Simo, J.C.and Ju, J.W. (1987a). Strain-based and Stress-based Continuum Damage Models .1. Formulation, Int. J. Solids Structures, 23(7): 821-840.

Simo, J.C.and Ju, J.W. (1987b). Strain-based and Stress-based Continuum Damage Models .2. Ccomputational aspects, Int. J. Solids Structures, 23(7): 841-869.

Siruguet, K. and Leblond, J.B. (2004a). Effect of Void Locking by Inclusions Upon the Plastic Behavior of Porous Ductile Solids-I: Theoretical Modeling and Numerical Study of Void Growth, Int. J. Plasticity, 20(2): 225-254.

Siruguet, K. and Leblond, J.B. (2004b). Effect of Void Locking by Inclusions Upon the Plastic Behavior of Porous Ductile Solids-part II: Theoretical Modeling and Numerical Study of Void Coalescence Growth, Int. J. Plasticity, 20(2): 255-268.

Steglich, D. and Brocks, W. (1997). Micromechanical Modelling of the Behaviour of Ductile Materials Including Particles, Comput. Mat. Sci., 9: 7-17.

Steglich, D. and Brocks, W. (1998). Micromechanical Modelling of Damage and Fracture of Ductile Materials, Fatigue and Fract. Eng. Mater. Struct., 21: 1175-1188.

Steglich, D., Siegmund, T. and Brocks, W. (1999). Micromechanical Modeling of Damage Due To Particle Cracking in Reinforced Metals, Comput. Mat. Sci., 16: 404-413.

Sukumar, N., Moes, N., Moran, B. and Belytschko, T. (2000). Extended Finite Element Method for Three Dimensional Crack Modelling, Int. J. Numer. Meth. Eng., 48(11): 1549-1570.

Sumpter, J.D.G (1993). An Experimental Investigation of the T Stress Approach. In: Constraint Effects in Fracture, ASTM STP 1171.

Sumpter, J.D.G. and Forbes, A.T. (1992). Constraint based analysis of shallow cracks in mild steel. In: TWI/EWI/IS International Conference on Shallow Crack Fracture Mechanics, Toughness Tests and applications, Cambridge, UN.

Tang, C.Y., Chow, C.L., Shen, W. and Tai, W.H. (1999). Development of a Damage-based Criterion for Ductile Fracture Prediction in Sheet Metal Forming, J. Mater. Processing Technol, 91: 270-277.

Tanguy, B. (2001). Modélisation De L'essai Charpy Par l'approche Locale de la Rupture. Application au cas de l'acier 16MND5 dans le domaine de la transition. Ph.D. Thesis, Ecole des Mines de Paris.

Tanguy, B. and Besson, J. (2002). An Extension of the Rousselier Model to Viscoplastic Temperature Dependent Materials, Int. J. Frac., 116(1): 81-101. 
Tanguy, B., Luu, T.T., Perrin, G., Pineau, A. and Besson, J. (2008). Plastic and Damage Behavior of a High Strength X100 Pipeline Steel: Experiments and Modelling, Int. J. Pressure Vessels and Piping, 85(5): 322-335.

Thomason, P.F. (1990), Ductile Fracture of Metals, Oxford, Pergamon Press.

Thomason, P. F. (1968). A Theory for Ductile Fracture by Internal Necking of Cavities, J. Ins. Metals, 96: 360-365.

Thomason, P. F. (1985a). A Three-dimensional Model for Ductile Fracture By the Growth and Coalescence of Microvoids, Acta Metall., 33(6): 1087-1095.

Thomason, P. F. (1985b). Three-dimensional Models for the Plastic Limit-Loads At Incipient Failure of the Intervoid Matrix In Ductile Porous Solids, Acta Metall., 33(6): 1079-1085.

Thomson, C.I.A., Worswick, M.J., Pilkey, A.K. and Lloyd, D.J. (2003). Void Coalescence Within Periodic Clusters of Particles, J. Mech. Phys. Solids, 51(1): 127-146.

Tvergaard, V. (1990). Material Failure by Void Growth To Coalescence, Adv. in Appl. Mech., 27: $83-151$.

Tvergaard, V. and Needleman, A. (1984). Analysis of the Cup-cone Fracture in a Round Tensile Bar, Acta Metall., 32: 157-169.

Voyiadjis, G.Z. and Kattan, P.I. (1999), Advances in Damage Mechanics: Metals and metal matrix composites, Elsevier.

Wang, C.C. (1970). New Theorem for Isotropic Functions (Part 1 and part 2). Arch. Rational Mech. Anal., 36: 166-223.

Worswick, M.J. and Pick, R.J. (1990). Void Growth and Constitutive Softening in a Periodically Voided Solid, J. Mech. Phys. Solids, 38: 601-625.

Xue, L. (2007). Damage Accumulation and Fracture Initiation in Uncracked Ductile Solids Subject to Triaxial Loading, Int. J. Solids Structures, 44: 5163-5181.

Xue, L. and Wierzbicki, T. (2008). Ductile Fracture Initiation and Propagation Modeling Using Damage Plasticity Theory, Eng. Fract. Mech., 75(1): 3276-3293.

Yamamoto, H. (1978). Conditions for Shear Band Localization in the Ductile Fracture of Void-Containing Materials, Int. J. Frac., 14(4): 347-365.

Zhang, K.S., Bai, J.B. and Francois, D. (2001). Numerical Analysis of the Influence of the Lode Parameter on Void Growth, Int. J. Solids Struct., 38(32-33): 5847-5856.

Zhang, Z.L. (1995a). Explicit Consistent Tangent Moduli with a Return Mapping Algorithm for Pressure-dependent Elastoplasticity Models, Comp. Meth. Appl. Mech. Eng., 121(1-4): 15-28.

Zhang, Z.L. (1995b). On the Accuracies of Numerical Integration Algorithms for Gursonbased Pressure-dependent Elastoplastic Constitutive Models, Comp. Meth. Appl. Mech. Eng., 121(1-4): 15-28.

Zhang, Z.L., Hauge, M. and Thaulow, C. (1996). Two-parameter Characterization of the Neartip Stress Fields for a Bi-material Elastic-plastic Interface Crack, Int. J. Frac., 79(1): 65-83.

Zhang, Z.L. and Niemi, E. (1994). Analyzing Ductile Fracture Using Dual Dilational Constitutive Equations, Fatigue and Fract. Eng. Mater. Struct., 17: 695-707.

Zhang, Z.L. and Niemi, E. (1995a). A Class of Generalized Midpoint Algorithms for the Gurson-Tvergaard Material Model, Int. J. Numer. Meth. Eng., 38(12): 2033-2053.

Zhang, Z.L. and Niemi, E. (1995b). A New Failure Criterion for the Gurson-Tvergaard Dilational Constitutive Model, Int. J. Frac., 70: 321-334.

Zhang, Z.L., Thaulow, C. and Hauge, M. (1997). Effects of Crack Size and Weld Metal Mismatch on the HAZ Cleavage Toughness of Wide Plates, Eng. Fract. Mech., 57(6): 653-664.

Zhang, Z.L., Thaulow, C. and Ødegård, J. (2000). A Complete Gurson Model Approach for Ductile Fracture, Eng. Fract. Mech., 67(2): 155-168. 